\title{
LOS COMPOSITES: CARACTERÍSTICAS Y APLICACIONES EN LA EDIFICACIÓN
}

\section{(COMPOSITES: CHARACTERISTICS AND APPLICATIONS IN BUILDING CONSTRUCTION)}

\author{
M. Olivares Santiago, C. Galán Marín, J. Roa Fernández
}

Dpto. Construcciones Arquitectónicas I. Escuela T. Superior de Arquitectura de la Universidad de Sevilla

Fecha de recepción: 24 IV-03

$$
\text { ESPAÑA }
$$

\begin{abstract}
RESUMEN
En este articulo los autores analizan los materiales compuestos desde el punto de vista de sus aplicaciones en el campo de la construcción. Se realiza un recorrido por los diferentes aspectos definitorios de los mismos: conceptos, tipos y características de cada uno de sus componentes, para, a continuación, desde un punto de vista práctico, analizar las propiedades, ventajas e inconvenientes de su aplicación en la construcción arquitectónica. Finalmente, se completa el trabajo con una exposición de casos reales en los que han sido aplicados estos materiales en el mundo de la construcción
\end{abstract}

\section{SUMMARY}

In this paper, the authors analyse composite materials from the point of view of their applications in the building construction field. An overview through the different distinctive aspects of composites is presented: concepts, types and characteristics of their components. Following, and from a practical point of view, advantages and disadvantages of the application of composites in construction are analysed. The article includes also a number of cases, real applications of these composite materials in the construction industry.

\section{MATERIALES COMPUESTOS}

\subsection{Concepto de los materiales compuestos}

Material compuesto es aquél constituido por dos, o más, componentes cuyas propiedades son superiores a las que tienen cada uno por separado, permaneciendo todos perfectamente identificables en la masa del elemento.

El material compuesto no es una invención humana, ya que existe en la propia naturaleza, así, la madera, es un ejemplo bastante típico puesto que está constituido por armaduras de fibras de celulosa envueltas en una matriz de resinas naturales; las fibras dan, en algunas direcciones, la resistencia necesaria al vegetal. También en el cuerpo humano existen materiales compuestos, como los huesos, formados por una especie de cemento cálcico y fibras de colágeno. En edificación, el primer material compuesto debido al hombre es el adobe, formado por barro y una armadura a base de paja, y también se utiliza, aunque en menor medida, el yeso armado con crines de caballo. Sin embargo, es el hormigón armado el material compuesto más famoso y más utilizado en la construcción y la ingeniería civil. El hormigón, como bien se sabe, presenta una buena resistencia a compresión pero malas características a tracción. El refuerzo con barras de acero consigue que el material compuesto resultante, el hormigón armado, tenga, por un lado, una muy buena resistencia a compresión, debida al hormigón, $y$, por otro, unas muy buenas resistencias a tracción, a flexión y a cizallamiento por la presencia del refuerzo metálico. La denominación de compuesto está justificada ya que el refuerzo y la matriz existen. Esta denominación también se emplea en materiales como el amianto-cemento, morteros y hormigones reforzados con fibras de acero, de vidrio o polimérica (Tabla I).

A partir de los 70, dentro de los denominados nuevos materiales han aparecido los "composites», que hoy en día son los nuevos materiales de mayor producción y aplicación, lo que explica que, en muchos casos, se crea que composites y nuevos materiales son la misma cosa. 
TABLA I

Materiales Compuestos

\begin{tabular}{|c|c|c|c|c|}
\hline & \multicolumn{2}{|c|}{ MATERIAL } & MATRIZ & $\begin{array}{c}\text { FIBRAS / } \\
\text { REFUERZO }\end{array}$ \\
\hline $\begin{array}{c}\text { EN LA } \\
\text { NATURALEZA }\end{array}$ & \multicolumn{2}{|c|}{ MADERA } & $\begin{array}{c}\text { RESINAS } \\
\text { NATURALES }\end{array}$ & $\begin{array}{l}\text { FIBRA DE } \\
\text { CELULOSA }\end{array}$ \\
\hline $\begin{array}{c}\text { EN EL CUERPO } \\
\text { HUMANO }\end{array}$ & \multicolumn{2}{|c|}{ HUESOS } & $\begin{array}{l}\text { CEMENTO } \\
\text { CÁLCICO }\end{array}$ & $\begin{array}{l}\text { FIBRA DE } \\
\text { COLÁGENO }\end{array}$ \\
\hline \multirow{9}{*}{$\begin{array}{c}\text { INVENCIÓN } \\
\text { HUMANA PARA } \\
\text { LA } \\
\text { CONSTRUCCIÓN }\end{array}$} & \multirow[b]{2}{*}{ ANTIGUEDAD } & ADOBE & BARRO & PAJA \\
\hline & & YESO ARMADO & YESO & $\begin{array}{l}\text { CRINES DE } \\
\text { CABALLO }\end{array}$ \\
\hline & \multirow{7}{*}{ MODERNAS } & $\begin{array}{l}\text { HORMIGÓN } \\
\text { ARMADO }\end{array}$ & HORMIGÓN & $\begin{array}{c}\text { ARMADURA DE } \\
\text { ACERO }\end{array}$ \\
\hline & & $\begin{array}{l}\text { AMIANTO } \\
\text { CEMENTO }\end{array}$ & $\begin{array}{l}\text { MORTERO DE } \\
\text { CEMENTO }\end{array}$ & AMIANTO \\
\hline & & \multirow{2}{*}{$\begin{array}{c}\text { MORTEROS Y } \\
\text { HORMIGONES } \\
\text { FIBROSOS }\end{array}$} & MORTERO & \multirow{2}{*}{$\begin{array}{l}\text { ACERO, VIDRIO, } \\
\text { POLIMÉRICAS, } \\
\text { CARBONO, } \\
\text { VEGETALES }\end{array}$} \\
\hline & & & HORMIGON & \\
\hline & & YESO ARMADO & YESO & $\begin{array}{c}\text { VIDRIO, } \\
\text { POLIMÉRICAS, } \\
\text { VEGETALES }\end{array}$ \\
\hline & & COMPOSITES & RESINA & $\begin{array}{c}\text { VIDRIO, } \\
\text { POLIMÉRICAS, } \\
\text { CARBONO, } \\
\text { ARAMIDA }\end{array}$ \\
\hline & & $\begin{array}{c}\text { MORTEROS } \\
\text { POLIMÉRICOS }\end{array}$ & RESINA & ÁRIDOS \\
\hline
\end{tabular}

Esencialmente, lo que se entiende por «composite» o material compuesto es una composición artificial, de fases diferentes y diferenciadas, aunque solidarias, cuyo mayor volumen lo ocupa su "fase matriz", componente de no muy alta densidad, de naturaleza polímera y sintética, en la mayoria de las preparaciones, que engloba una segunda fase, "fase de refuerzo", compuesta generalmente a base de fibras (también pueden ser partículas o láminas), con resistencias a la tracción, muy superiores a la que posee la matriz. Las partículas, fibras o láminas, englobadas dentro de la matriz, actúan como armaduras o refuerzos de la misma, pudiendo llegar a absorber la práctica totalidad de las cargas que se aplican al compuesto.

No les parece muy adecuado a algunos hablar de "composite" existiendo en castellano la palabra "compuesto", sin embargo, se ha generalizado su uso para definir a aquellos materiales compuestos, de reciente aparición, cuya matriz es polimérica, para distinguirlos de los de matriz cementicia o de yeso. Las últimas investigaciones están ampliando esta denominación a los materiales compuestos de matriz metálica y cerámica, aunque los mismos aún no tienen aplicaciones dentro del campo de la construcción arquitectónica.

\subsection{Componentes de los composites}

Casi todos los denominados composites están constituidos por dos fases: una, sustentante o matriz, y otra, reforzante, que está inmersa o firmemente adherida a la primera.

La fase matriz del composite suele ser la más tenaz, aunque también la menos resistente y dura. La fase reforzante suele ser, por el contrario, la de mayor resistencia y con más alto módulo elástico, pero también la de mayor fragilidad. La combinación y compensación de dureza y blandura, fragilidad y tenacidad en los compuestos bien discñados hace que estos materiales tengan muchas aplicaciones y respondan a muy variadas exigencias constructivas. En definitiva, podemos decir que la fibra aporta rigidez y resistencia y que la matriz es flexible y poco resistente, aglomera las fibras, les da forma y transmite los esfuerzos entre fibras.

Dentro de los composites se pueden establecer tres tipos (Figura 1):

Composites particulados, cuya fase inmersa en la matriz se compone de partículas con formas más o menos aproximadas a la esférica. 
Composites fibrosos, llamados asi cuando el material de refuerzo está formado por fibras, esto es, por elementos en los que una dimensión predomina notablemente sobre las otras dos. Dentro del compuesto, las fibras de refuerzo pueden quedar orientadas de diversas formas (Figura 2).

a) de forma unidireccional (fibras largas)

b) de manera aleatoria (fibras cortas)

c) con disposición ortogonal (mallas ortogonales)

d) en varias capas alternadas.

Finalmente, los composites laminados, son aquéllos en los que suelen alternarse las fases componentes en forma laminar, y no siempre con espesores semejantes.

\subsubsection{Las matrices. Tipos y características}

La matriz rodea, protege y soporta las fibras para: proteger a las fibras de las condiciones medioambientales, proteger a las superficies de las fibras contra el desgaste, proteger a las fibras frente a los esfuerzos de compresión y prevenir el pandeo de las fibras.

El tipo de matriz utilizado en la fabricación del composite influye, evidentemente, en algunas de las características del producto final. Influye muy poco en las propiedades mecánicas de tracción y flexotracción, pero, sin embargo, bastante en las propiedades mecánicas de cortante, $\mathrm{y}$, de manera notable, en las propiedades mecánicas de compresión. Por otro lado influye también mucho en las condiciones de fabricación (viscosidad, punto de fusión, temperatura de curado...)

\subsubsection{Tipos de matrices}

Las matrices de los composites, de una manera muy general, se pueden clasificar en termoestables o termoplásticas, según las variedades indicadas en la Tabla II.

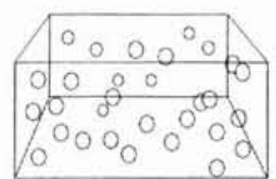

COMPUESTOPARTICUADO

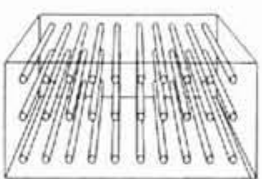

COMPUESTOFBROSO

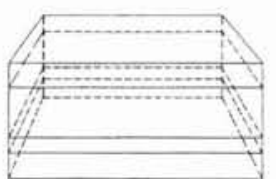

COMPUESTOLAMNADO

Figura 1.- Tipos de Materiales Compuestos.
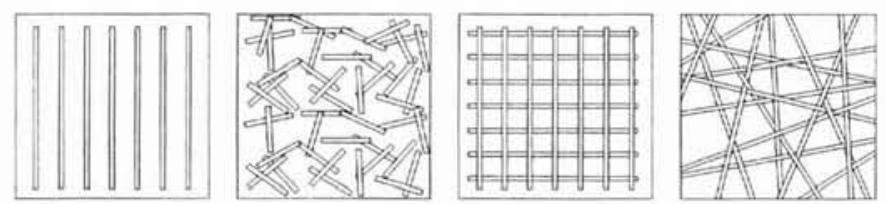

a)

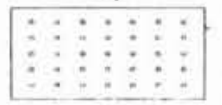

b)

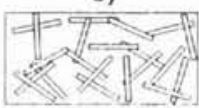

c)

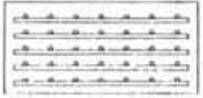

d)

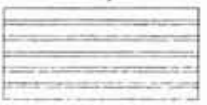

Figura 2.- Tipos de Composites Fibrosos.

TABLA II

Clasificación de matrices en los composites

\begin{tabular}{|c|c|}
\hline \multicolumn{2}{|c|}{ MATRICES POLIMÉRICAS U ORGÁNICAS } \\
\hline Termoestables & Termoplásticas \\
\hline $\begin{array}{c}\text { Polićsteres insaturados (UP) } \\
\text { Viniléster o ésteres vinilicos (VU) } \\
\text { Epoxi (EP) } \\
\begin{array}{c}\text { Fenólicas (PF) } \\
\text { Polyimidas (PI) }\end{array}\end{array}$ & $\begin{array}{c}\text { Nylon } \\
\text { Poliésteres saturados (PET-PBT) } \\
\text { Policarbonato (PC) } \\
\text { Poliacetato } \\
\text { Poliamida (PA) }\end{array}$ \\
$\begin{array}{c}\text { Polićter-Éter Ketona (PEEK) } \\
\text { Polisulfonato (PSUL) }\end{array}$ \\
\hline \multicolumn{2}{|c|}{ Elastóremos } \\
Poliuretano(PU) \\
Siliconas (SI)
\end{tabular}


Actualmente también se está denominando composite a los materiales compuestos de matriz metálica y cerámica. Además de sus buenas prestaciones mecánicas, estos composites, frente a sus homólogos de matriz orgánica tienen la ventaja de poder ser utilizados con altas temperaturas; sin embargo, son aún muy costosos y están en fase de investigación, o han tenido muy pocas aplicaciones en el campo industrial, por lo que se puede afirmar que su uso en la construcción queda todavía un poco lejano.

Dentro del campo de la construcción, las matrices más empleadas son las termoestables, y, dentro de éstas, las de poliéster, viniléster, fenólicas y epoxi, por lo que sólo vamos a analizar a continuación las características de éstas.

A pesar de que todas estas resinas tienen, cada una de ellas, unas propiedades muy específicas, sin embargo, las matrices termoestables reúnen, en general unas características comunes que enumeramos a continuación:

-Viscosidad muy baja antes del curado.

-Estabilidad térmica.

-Resistencia química.

-Poca fluencia y relajación por tensión.

-Buena capacidad de preimpregnado.

-Facilidad de fabricación.

-Economía.

\section{RESINAS DE POLIÉSTER}

Son las más usadas, su obtención industrial da lugar a un compuesto sólido, que hay que disolver para obtener la fluidez suficiente a fin de que la impregnación de las fibras sea posible, por lo que se suministra disuelta en estireno, que va a participar en la reticulación. Suele venir mezclada con un acelerador que ayuda al catalizador a descomponerse y pueda comenzar así la reacción química de reticulación. Hay muchos tipos de resinas de poliéster comercializadas
(Tabla III), para muy diferentes clases de aplicaciones, pudiéndose conseguir composites con distintas calificaciones de resistencia al fuego (M1, M2 o M3), composites con una alta resistencia a los rayos U.V. y a la humedad, con mayor resistencia química, con una másresistencia más alta al impacto, con resistencia a altas temperaturas (hasta $140^{\circ} \mathrm{C}$ ), etc. El uso de distintas clases de catalizadores y aceleradores aumenta las posibilidades de aplicaciones de estas resinas.

Los composites realizados con las resinas de poliéster responden a las siguientes propiedades:

- Baja viscosidad, buena trabajabilidad.

- Tiempo de curado rápido.

- Muy alta contracción durante el curado.

- Gran rango de aplicaciones debido a los diferentes tipos de resinas de poliéster que pueden conseguirse.

- Posibilidades de curado tanto a temperatura ambiente como a altas temperaturas.

- Buena resistencia eléctrica.

- Magnífica relación calidad/precio.

- Buenas propiedades del composite, aunque inferiores a los conseguidos con algunas otras resinas.

\section{RESINAS VINIL-ÉSTER}

Su manejo, aspecto y olor es similar a las de poliéster al venir también disueltas en estireno. Su contracción durante la reticulación es menor, originando menos huecos y, por tanto, aumentando todas las propiedades, tanto mecánicas como de resistencia química y durabilidad. La resistencia al impacto mejora sustancialmente, dando lugar al reforzarla con "kevlar" a composites de alta tenacidad.

Las principales propiedades de los composites realizados a base de resinas vinil-éster son las siguientes:

- Buenas cualidades mecánicas, y, de forma particular, excelentes resistencia a la fatiga.

TABLA III

Tipos de resinas de poliéster más utilizadas y sus aplicaciones

\begin{tabular}{|l|l|}
\hline TIPOS & APLICACIONES \\
\hline Ortoftálicas & $\begin{array}{l}\text { Semirrígidas: estratificados industriales, placas onduladas. } \\
\text { Rigidas: barnices, preimpregnados. }\end{array}$ \\
\hline Isoftálicas & Gel coats, depósitos, ingenieria química... \\
\hline Tereftálicas & Ingenieria química, estratificados con alta resistencia quimica. \\
\hline Tetrahidroftálicas & Barnices, depósitos de alimentos, cubas. \\
\hline Bisfenólicas & Aplicaciones anticorrosión, alta resistencia quimica. \\
\hline Resinas del ac. tetracloroftálico & Comportamiento al fuego mcjorado. \\
\hline Resinas del ac. Het & Resistencia al fucgo, anticorrosión. \\
\hline Resinas al MMA & Estratificados para el transporte, placas, cúpulas. \\
\hline
\end{tabular}


- Excelente fluidez, o baja viscosidad, que facilita su impregnabilidad y moldeo.

- Buena adhesión con las fibras de refuerzo.

- Resistencia a la corrosión incluso en agua caliente.

- Estabilidad contra agentes químicos y disolventes.

- Tiempo de curado rápido.

- Alta contracción durante el curado.

\section{RESINAS FENÓLICAS}

Su uso es muy adecuado en construcción debido a las altas temperaturas que pueden llegar a soportar, además tienen la ventaja de que cuando arden lo hacen sin emitir gases tóxicos. Reforzado con fibra de vidrio se consiguen productos calificados como M0. Existe resina para la fabricación por contacto manual, prensa y preimpregnado.

Las principales propiedades de los composites realizados a base de resinas fenólicas son las siguientes:

- Excelentes características eléctricas.

- Buena resistencia a temperaturas elevadas.

- Muy buena resistencia al fuego.

- Resistencia a la abrasión.

- Buena resistencia al ataque químico y de forma especial al de los disolventes orgánicos.

- Excelente adhesión a otras resinas, como epoxi, ureaformol, etc.

- Estabilidad dimensional.

\section{RESINAS EPOXI}

Es la de mayor precio, pero también la de mejores propiedades. Presenta una gran capacidad para adherirse a la mayoría de las superficies, y, en consecuencia, al igual que pasa con las resinas fenólicas, permite unos porcentajes muy altos de refuerzo. Es completamente diferente a las resinas de poliéster y exige una preparación mucho más estricta durante su uso. Mientras que en las resinas de poliéster el porcentaje de catalizador no es excesivamente importante, variando con el mismo la velocidad de reacción, con las resinas epoxi es necesario el uso de balanzas de precisión para la dosificación del catalizador, siendo necesario cambiar el tipo del mismo cuando quiera variarse la velocidad de reacción. Son más seguras al no ser tan inflamables y más tenaces al tener una alta capacidad de alargamiento. También existe en el mercado una alta gama de tipos de resinas epoxi.

Las principales propiedades de los composites realizados a base de resinas epoxi son las siguientes:

- Excelentes propiedades del composite en general.

- Baja retracción durante el curado.

- Buen comportamiento a temperaturas elevadas, hasta $180^{\circ} \mathrm{C}$.

- Buena resistencia y estabilidad ante los agentes químicos y disolventes.

- Ausencia de volátiles durante el curado.
- Muy buenas propiedades eléctricas.

- Buena adhesión a casi todas las fibras.

- Largo tiempo de curado.

- Coste relativamente alto.

Las caracteristicas y propiedades del composite van a depender mucho del tipo de matriz utilizada. En la Tabla IV se dan algunos datos comparativos de las características más importantes de las cuatro resinas poliméricas termoestables que hemos definido en los párrafos precedentes.

TABLA IV

Propiedades de las matrices poliméricas termoestables

\begin{tabular}{|c|c|c|c|c|}
\hline \multicolumn{5}{|c|}{ MATRICES TERMOESTABLES } \\
\hline PROPIEDADES & 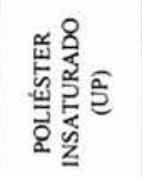 & 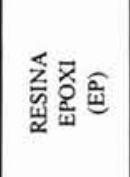 & 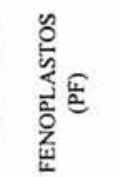 & 充总 \\
\hline Densidad $\left(\mathrm{g} / \mathrm{cm}^{2}\right)$ & $1.17-1.26$ & $1.17-1.25$ & $1.25-1.3$ & $1.17-1.25$ \\
\hline $\begin{array}{c}\text { Alargam. } \\
\text { a rotura (\%) }\end{array}$ & $<3$ & $6-8$ & $<3$ & $3.5-7$ \\
\hline Fluencia & \multicolumn{4}{|c|}{ Muy baja } \\
\hline $\begin{array}{l}\text { Temperatura de } \\
\text { moldeo }\left({ }^{\circ} \mathrm{C}\right)\end{array}$ & $\begin{array}{c}\text { T.Amb. a } \\
180\end{array}$ & $\begin{array}{c}\text { T.Amb. a } \\
170\end{array}$ & 150 a 190 & T.Amb a 175 \\
\hline $\begin{array}{l}\text { Temp. de } \\
\text { rebland. }\left({ }^{\circ} \mathrm{C}\right)\end{array}$ & $80-160$ & $80-130$ & $100-150$ & $100-150$ \\
\hline $\begin{array}{c}\text { Resistencia a } \\
\text { deform. térm. } \\
\left({ }^{\circ} \mathrm{C}\right)\end{array}$ & $55-90$ & $60-110$ & 150 & $55-85$ \\
\hline $\begin{array}{l}\text { Cualidades de } \\
\text { flujo a temper. } \\
\text { trabajo }\end{array}$ & \multicolumn{4}{|c|}{ Muy buenas (fluidos) } \\
\hline $\begin{array}{l}\text { Calor de } \\
\text { reacción }\end{array}$ & \multicolumn{4}{|c|}{$\begin{array}{l}\text { Reacción exotérmica con mayor desarrollo } \\
\text { térmico según la pieza }\end{array}$} \\
\hline $\begin{array}{l}\text { Contracción } \\
\text { fraguado }(\%)\end{array}$ & \begin{tabular}{c|}
$6-10$ \\
$1.8-2.4$
\end{tabular} & $1-3$ & $0.5-1.5$ & $0.1-1$ \\
\hline $\begin{array}{l}\text { Contracciones } \\
\text { desiguales }\end{array}$ & \multicolumn{4}{|c|}{$\begin{array}{c}\text { Contracción compensable por adición de } \\
\text { partículas termoplásticas }\end{array}$} \\
\hline \multirow{2}{*}{$\begin{array}{l}\text { Contracción } \\
\text { posterior }(\%)\end{array}$} & \multicolumn{4}{|c|}{ Para masas de moldco casi nula } \\
\hline & $<3$ & Nula & $<0.4$ & Nula \\
\hline $\begin{array}{l}\text { Tiempo de } \\
\text { almacenaje } \\
\text { (meses) }\end{array}$ & $\begin{array}{l}<6 \sin \\
\text { aire/luz }\end{array}$ & $\begin{array}{c}6-12 \\
\text { según } \\
\text { present }\end{array}$ & $\begin{array}{l}<6 \sin \\
\text { hum. a } \\
\text { T.Amb }\end{array}$ & $\begin{array}{l}<6 \mathrm{a} \\
\text { T.Amb }\end{array}$ \\
\hline Resistente a & $\begin{array}{c}\text { Agua } \\
\text { s.acuosas } \\
\text { Fucl } \\
\text { Gasolina }\end{array}$ & $\begin{array}{c}\text { Alcohol } \\
\text { Gasolina } \\
\text { Benzol } \\
\text { A. miner } \\
\text { Grasas }\end{array}$ & $\begin{array}{c}\text { Agua } \\
\text { Accites } \\
\text { Grasas } \\
\text { Gasolina } \\
\text { Benzol } \\
\text { Alcohol } \\
\end{array}$ & $\begin{array}{l}37 \% \text { HCL } \\
\text { Diox.cloro } \\
\text { Agua mar } \\
\text { Alquitranes }\end{array}$ \\
\hline No resistente a & $\begin{array}{c}\text { A gua hirv } \\
\text { Ácidos c. } \\
\text { Lejia c. } \\
\text { Benzol } \\
\text { Alcohol } \\
\text { Toluol }\end{array}$ & $\begin{array}{c}\text { Agua } \\
\text { hirv. } \\
\text { Ésteres c. } \\
\text { Álcalis c. } \\
\text { Cetonas } \\
\text { Acctona }\end{array}$ & $\begin{array}{c}\text { Ácidos } \\
y \\
\text { Alcalis } \\
\text { concentr. }\end{array}$ & $\begin{array}{c}\mathrm{SO}_{4} \mathrm{H}_{2}(75 \%) \\
\text { Agua hirv. } \\
\mathrm{NaOCl}(6 \%) \\
\mathrm{NaOII}(15 \%)\end{array}$ \\
\hline Inflamabilidad & $\begin{array}{c}\text { No } \\
\text { autocxting }\end{array}$ & $\begin{array}{c}\text { Dificilm. } \\
\text { inflamabl } \\
\text { Arde }\end{array}$ & $\begin{array}{c}\text { Dific. } \\
\text { Inflamab. } \\
\text { No funde } \\
\end{array}$ & $\begin{array}{c}\text { No } \\
\text { autocxting. }\end{array}$ \\
\hline Reparación & \multicolumn{4}{|c|}{ Sobrclaminación y cncolado } \\
\hline
\end{tabular}




\subsubsection{Las fibras. Tipos y caracteristicas}

Las fibras del refuerzo han de ser fuertes, resistentes, rígidas, ligeras y con una temperatura de fusión alta, prefiriéndose las fabricadas con materiales que tengan límites plásticos específicos y módulos de elasticidad específicos altos. La influencia de las fibras sobre las características totales del composite es definitiva. Las propiedades del composite son función tanto del porcentaje como de la orientación de las fibras.

El mayor porcentaje de las fibras incrementa la resistencia y rigidez del composite; pero no debe olvidarse que el porcentaje máximo deberá estar limitado para asegurar así que la totalidad de la superficie de las fibras quede recubierta con el material tenaz de la matriz, este límite máximo suele establecerse en el $80 \%$.

La orientación del refuerzo también influye de una forma determinante en las características del composite, y, fundamentalmente, en su módulo de elasticidad (Figura 3). Las fibras contínuas y colocadas paralelas y unidireccionalmente, originan la estructura más resistente, cuando las cargas se aplican paralelas a las fibras, aunque con el problema de una fuerte anisotropía (Rovings). Por ello, se utiliza también la colocación de fibras en disposición ortogonal cruzadas en una o varias capas, sacrificando las máximas resistencias posibles en aras de una mayor uniformidad estructural del composite (tejidos).También es frecuente que las fibras estén orientadas aleatoriamente en todas direcciones, o sin ninguna dirección predominante, siendo, en este caso, las características del composite bastante menores.

Asimismo, existe una relación entre la orientación y el porcentaje de las fibras, así cuando se trata de fibras continuas colocadas unidireccionalmente puede llegarse al máximo porcentaje de fibras, establecido en un $70-80 \%$. En el caso de composites con el refuerzo colocado ortogonalmente los porcentajes de las fibras se reducen a un $45-65 \%$. Y finalmente en el caso de distribución aleatoria de la fibra el porcentaje se reduce hasta quedar establecido entre un 20 $y$ un $40 \%$.

Los principales tipos de fibras utilizadas en los composites pueden clasificarse en cuatro grandes grupos: vidrio, sintéticas, carbono y aramida.

\section{FIBRAS DE VIDRIO}

Son las más utilizadas como refuerzo en los composites aplicados a la construcción, debido, fundamentalmente, a la excelente relación existente entre características y precio.

Las fibras de vidrio están elaboradas con las mismas materias primas que el vidrio: silice, cal, alúmina y magnesita, a las cuales se les añaden ciertos óxidos en porcentajes muy estrictos, según los tipos de fibras que se quieran obtener. Todos estos componentes se mezclan y trituran hasta conseguir una mezcla homogénea que se introduce en un horno de fusión a la temperatura de $1550^{\circ} \mathrm{C}$, en el cual la mezcla pasa progresivamente a un estado líquido. El vidrio en estado líquido pasa por las hileras, por centenares de orificios de 1 a $2 \mathrm{~mm}$. de diámetro, a la salida de los cuales son estirados mecánicamente hasta conseguir unos filamentos de 5 a 24 micras, dependiendo de las aplicaciones. Posteriormente se revisten estos filamentos con una dispersión acuosa de compuestos, generalmente orgánicos, operación denominada "ensimaje" que garantiza la unión entre filamentos y la protección del hilo. Los filamentos, una vez revestidos, se reúnen para formar el hilo al que finalmente se le da un acabado textil o plástico (Figura 3).

Las presentaciones industriales de la fibra vidrio para su uso como material de refuerzo de las matrices orgánicas son las siguientes (Figura 4):

- Mat: fieltros de hilos cortados o contínuos aglomerados entre sí mediante un ligante químico.

- Roving: bobinas de filamentos (roving directo) o hilos de vidrio (roving ensamblado) que han recibido un ensimaje plástico.

- Tejido: superficies constituidas por mechas de roving directo en trama y urdimbre, tratados principalmente con ensimaje plástico.

- Hilos cortados: hilos cortados generalmente en longitudes de 3 a $12 \mathrm{~mm}$.

- Fibras molidas: fibras trituradas hasta longitudes comprendidas entre 0,1 y $0,02 \mathrm{~mm}$. Manteniendo su diámetro entre 10 y 17 micras.

Las principales características de estas fibras son las siguientes:

- Buenas resistencias mecánicas.

- Buen aislante eléctrico.

- Baja densidad.

- Incombustibilidad.

- Estabilidad dimensional.

- Imputrescibilidad.

- Buena flexibilidad.

- Bajo costo.

- Bucna resistencia a agentes químicos.

- Baja rigidez.

- Menor resistencia a la fatiga que otras fibras.

- Alta dureza.

Existen muchos tipos de fibras de vidrio, ya que dependiendo del porcentaje de cada uno de sus componentes pueden obtenerse diferentes formulaciones, adecuada cada una de ella, a unas características determinadas. En la Tabla $\mathrm{V}$, puede observarse la composición de los diferentes tipos de fibras de vidrio. 


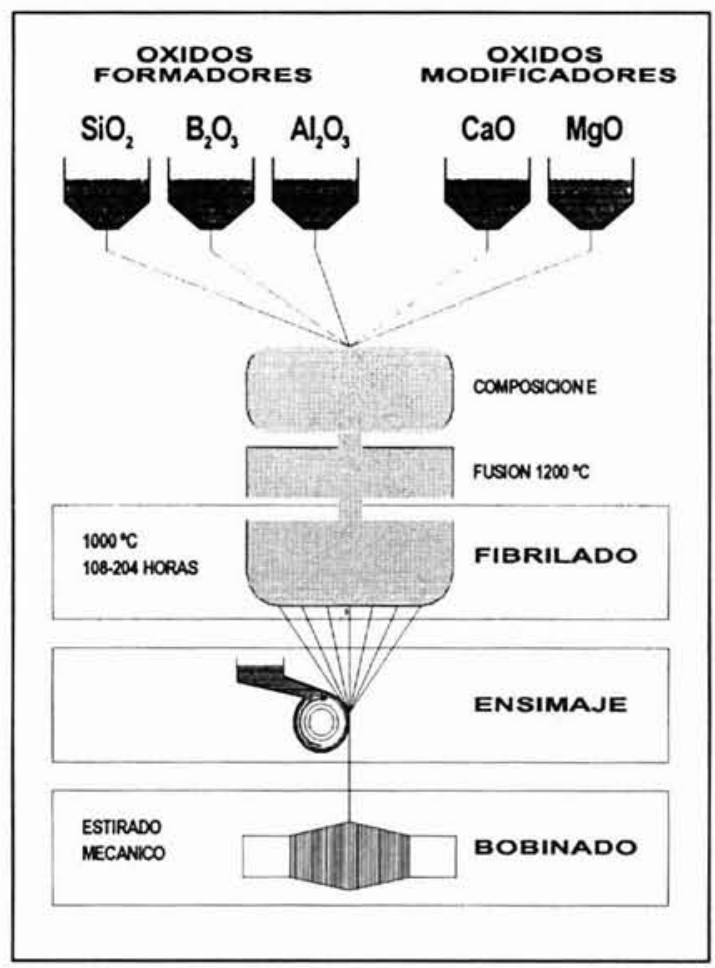

Figura 3.- Proceso de fabricación de la fibra de vidrio $E$.

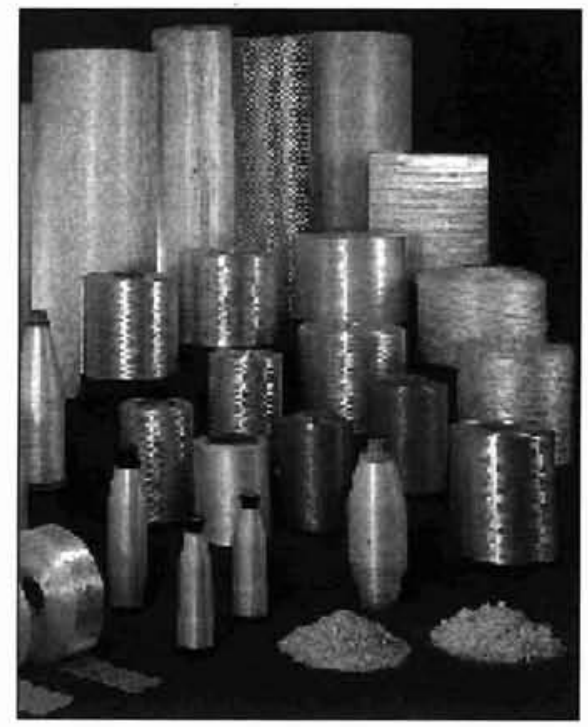

Figura 4.- Diferentes presentaciones de la fibra de vidrio.

TABLA V

Composición de los diferentes tipos de fibras de vidrio

\begin{tabular}{|c|c|c|c|c|c|c|c|c|c|c|c|c|c|c|}
\hline \multicolumn{2}{|c|}{ Tipos vidrios } & 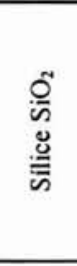 & 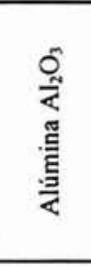 & $\frac{0}{3}$ & 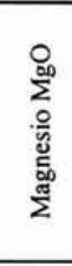 & 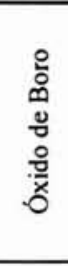 & 点 & 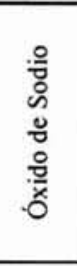 & 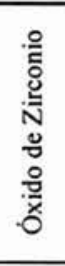 & 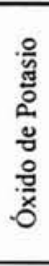 & 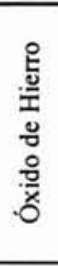 & 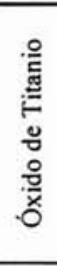 & 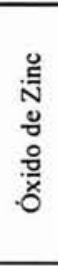 & 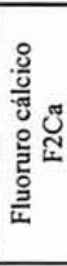 \\
\hline Polival. & $\mathrm{E}$ & $53-54$ & $14-15,5$ & \multicolumn{2}{|c|}{ 20-24 sumados } & $6,5-9$ & $0-0,7$ & \multicolumn{5}{|c|}{ Total $\# 1$} & - & - \\
\hline \multirow{2}{*}{$\begin{array}{c}\text { Resistent. } \\
\text { a } \\
\text { ácidos }\end{array}$} & A & $70-72$ & $0-2,5$ & $5-9$ & $4-1$ & $0-0,5$ & - & $12-15$ & - & 1 & - & - & - & - \\
\hline & $\mathrm{C}$ & $60-65$ & $2-6$ & 14 & $1-3$ & $2-7$ & - & $8-10$ & - & - & - & - & - & - \\
\hline \multirow{2}{*}{\multicolumn{2}{|c|}{$\begin{array}{l}\text { Resistentes a } \\
\text { álcalis }\end{array}$}} & $65-70$ & - & $4-8$ & - & - & - & $14-20$ & $\cdot$ & $0-3$ & - & $6-12$ & - & - \\
\hline & & $62-75$ & $0-6$ & - & - & $0-6$ & - & $13-2 \mid$ & 7.17 & - & $0-5$ & $0-4$ & $1-10$ & $0-2$ \\
\hline \multirow{2}{*}{$\begin{array}{l}\text { Alta } \\
\text { resistenc. } \\
\text { macánica }\end{array}$} & $\mathrm{R}$ & 60 & 25 & 6 & 9 & - & - & $\cdot$ & $\cdot$ & - & - & - & $\cdot$ & - \\
\hline & S & $62-65$ & $20-25$ & $\cdot$ & $10-15$ & $0-1.2$ & - & $0-1,1$ & - & $\cdot$ & - & - & - & - \\
\hline Dieléctr. & D & $73-74$ & - & \multicolumn{2}{|c|}{$0.5-0.6$ sumados } & $22-23$ & - & 1,3 & $\cdot$ & 1.5 & - & - & - & - \\
\hline
\end{tabular}

Los tipos de fibras de vidrios más corrientes son los siguientes:

Fibra de vidrio E: cs la más utilizada, ya que representa el $90 \%$ del refuerzo utilizado en los composites. También es la que más se utiliza en la industria textil. Tiene muy buenas propiedades eléctricas. Es durable y de baje coste. Poca absorción de humedad.
Fibra de vidrio A: tiene un alto porcentaje de silice. Sus propiedades mecánicas son inferiores y tiene un módulo más bajo que el vidrio $\mathrm{E}$. Se utiliza como reforzante y tiene una gran resistencia química. Es resistente a medios alcalinos.

Fibra de vidrio B: es borosilicato de calcio de bajo contenido en álcalis. De gran durabilidad, posee excelentes propiedades eléctricas. 
Fibra de vidrio $\mathrm{S}$ : tiene muy buenas resistencias mecánicas $y$, en especial, una alta resistencia a la tracción. Muy estable térmicamente se utiliza, fundamentalmente, en aeronáutica.

Fibra de vidrio $\mathbf{C}$ : de altas resistencias químicas. Es un vidrio intermedio entre el $\mathrm{A}$ y el E. Se utiliza en las capas superficiales de elementos expuestos a la corrosión o de estructuras anticorrosión

Fibra de vidrio $\mathbf{R}$ : tiene unas altas resistencias mecánicas, siendo su resistencia a la tracción y su módulo de elasticidad muy superiores a los de los otros vidrios. Se emplea, sobre todo, en los campos de la aeronáutica, aviación, armamento y, en general, cuando se exigen materiales muy resistentes a la fatiga, la temperatura y la humedad.

Fibra de vidrio D: tiene unas altas propiedades dieléctricas por lo que su empleo es recomendado en la construcción de materiales electrónicos, de comunicación y como material permeable a las ondas electromagnéticas. Se utiliza en la fabricación de radares y ventanas electromagnéticas.

Fibra de vidrio AR: es la que se utiliza para armar los morteros de cemento (GRC) por ser resistente a los álcalis del cemento.

\section{FIBRAS SINTÉTICAS}

Las fibras sintéticas existentes se fabrican a partir de polímeros termoplásticos constituyendo, en general, unos materiales muy estables y duraderos. Las más conocidas son las siguientes:

Polipropileno: son fibras de homopolímero de propileno $100 \%$ fibrilado e imprimado, de diferentes longitudes según la aplicación. Es un material inerte, compatible con todo tipo de cementos y aditivos, por lo que se utiliza para armar morteros de cemento y en la construcción de materiales geosintéticos. Tiene muy buenas propiedades mecánicas.

Polietileno: se fabrican, al igual que las de propileno, a partir de las poliolefinas y, como ellas, se utilizan para armar los morteros de cemento y en la construcción de materiales geotextiles.
Nylon: se consiguen a partir de la poliamida, por lo que a veces se denominan de esta forma. Con buena resistencia a la tracción y a la extensión se emplea en el armado de suelos, en materiales geosintéticos.

Poliéster: además de emplearse en el campo de los geotextiles, son las fibras que, junto a las de vidrio, más se utilizan en la arquitectura textil combinadas con una matriz termoplástica, normalmente policloruro de vinilo (PVC).

\section{FIBRAS DE CARBONO}

Se obtienen a partir de una fibra previa, a la cual se le llama "precursor" y que puede ser el PAN (poliacrilonitrilo), en cuyo caso el proceso se denomina PAN, o el PITCH, que es una especie de alquitrán, en cuyo caso el proceso se denomina PITCH. En ambos procedimientos, se pasa por unas fases sucesivas de: tratamiento térmico e hilado, calentamiento hasta 1.000 ó $2.000^{\circ} \mathrm{C}$ según el proceso, carbonización y grafitización. De esta forma se consiguen fibras de carbono de alto módulo con alta o baja resistencia. Previo a la grafitización se han obtenido fibras de carbono de bajo módulo y alta resistencia. Por lo que a las fibras de carbono de alto módulo deberían denominarse fibras de grafito (Figuras 5 y 6 ).

Las características más importantes de las fibras de carbono o grafito son las siguientes:

- Gran rigidez.

- Bajo peso.

- Alta resistencia.

- Coeficiente de dilatación muy bajo, lo que le proporciona una gran estabilidad dimensional a las estructuras.

- Conductividad térmica elevada.

- Alto coste.

- Baja resistencia al choque.

- Favorece corrosiones de tipo galvánico debido a las diferencias de potencial que genera en contacto con los metales.

La relación caracteristicas/precio es muy alta, por lo que su uso en la edificación es en aplicaciones muy específicas.

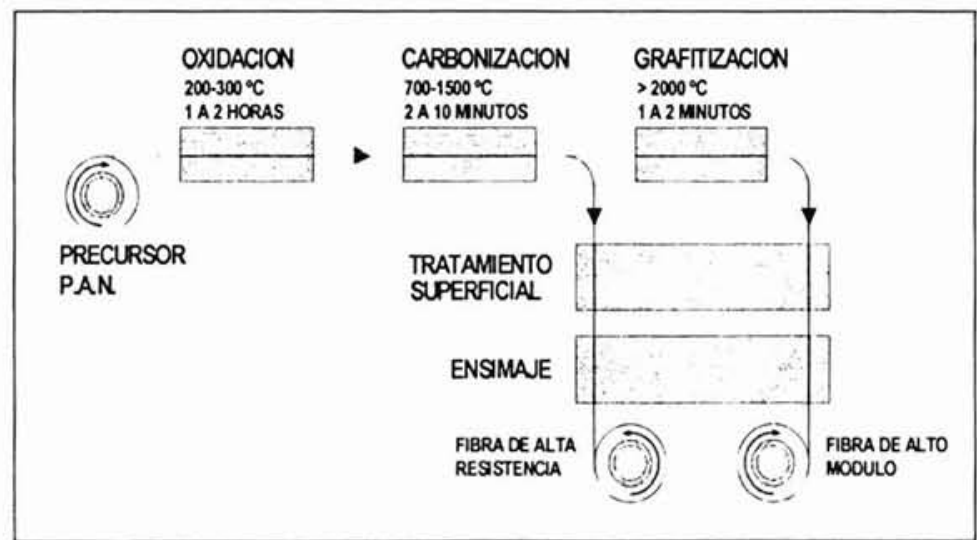

Figura 5. - Proceso de fabricación de la fibra de carbono.

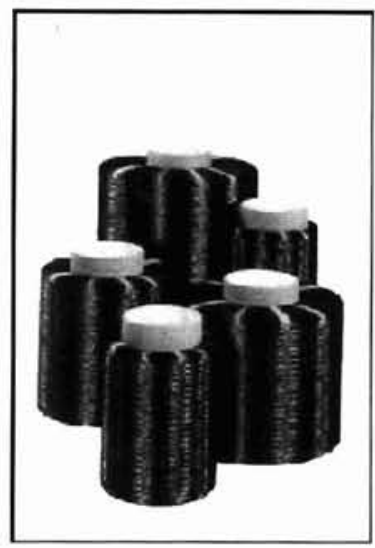

Figura 6. - Presentación de la fibra de carbono. 
Actualmente se están utilizando, cada vez de forma más frecuente, composites carbono-epoxi en la reparación o refuerzo de estructuras de hormigón.

\section{FIBRAS DE ARAMIDA}

Las fibras de aramida son orgánicas y sintéticas y se obtienen mediante un proceso de extrusión e hilado a partir de poliamidas aromáticas del tipo politereftalato de polifenilendiamida. Existen distintos tipos de fibras de aramida siendo el Kevlar la que ha tenido el mayor éxito comercial (Figura 7). Las cuatro principales son: Kevlar RI, Kevlar 29, Kevlar 49 y Nomex. De todas ellas es el Kevlar 49 la fibra que más se utiliza para los composites de altas prestaciones.

Las principales características de las fibras de aramida en general y del Kevlar en particular, son:

- Muy bajo peso.

- Gran resistencia al impacto.

- Gran resistencia a la tracción.

- Muy baja resistencia a la compresión.

- Escasa adherencia a matrices termoplásticas.

- Resistencia a agentes químicos.

- Estabilidad mecánica entre $-30^{\circ} \mathrm{C} \mathrm{y}+200^{\circ} \mathrm{C}$.

En la Tabla V se ha hecho un estudio comparativo de las diferentes fibras utilizadas en los composites.

\subsubsection{Las cargas. Tipos y características}

Las cargas se añaden a las matrices y fibras para conseguir mejorar algunas de sus cualidades o para reducir el costo total del composite. Pueden ser de dos tipos: reforzantes o no reforzantes.

Las cargas reforzantes suelen tener forma esférica, huecas o macizas, para evitar de esa forma las concentraciones de tensiones y pueden ser: de vidrio, de carbono o poliméricas.

Las no reforzantes, son fundamentalmente de origen mineral, por lo que son muy baratas y hay que incorporarlas a la mezcla en proporciones que dependerán de las características que se quieran conseguir. Las más empleadas son los carbonatos, los silicatos y las sílices. Las cargas no reforzantes pueden tener como finalidad, principalmente, la de abaratar el producto, aumentar su resistencia al fuego o incrementar su capacidad conductora, ya sea de electricidad o calor.

\subsubsection{Los aditivos. Tipos y características}

Los aditivos suelen utilizarse en la fabricación de los composites cada vez con más frecuencia, aunque en proporciones inferiores a las empleadas para las cargas. Pueden ser de varios tipos: lubricantes, desmoldeantes, estabilizantes, ignifugantes, fungicidas o colorantes.

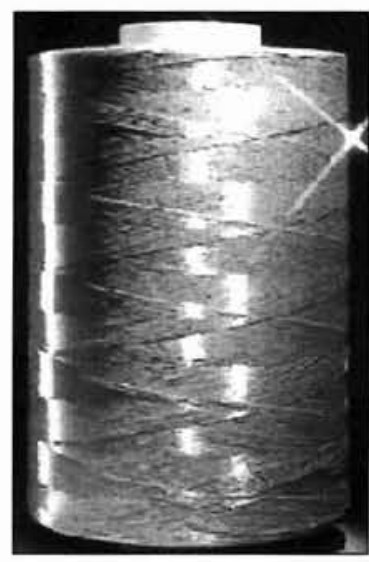

Figura 7.- Fibra de aramida.

Es muy importante que el aditivo elegido sea compatible con los demás componentes del compuesto y que sus propiedades sean, como mínimo, las exigidas al composite, para no disminuir las características exigidas al mismo.

\subsection{Compatibilidad de matrices y fibras. Las buenas parejas}

No todas las matrices pueden ser reforzadas con todas las fibras, por lo que es muy importante analizar las compatibilidades entre las diferentes fibras y matrices.

En la Tabla VI, se han resumido las compatibilidades entre las matrices y fibras más utilizadas en la fabricación de los composites atendiendo a dos niveles: combinación buena

TABLA VI

Compatibilidades entrefibras y matrices para composites

\begin{tabular}{|c|c|c|c|c|}
\hline MATRICES & 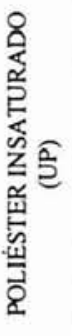 & 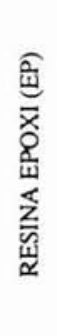 & 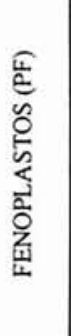 & 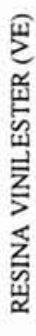 \\
\hline VIDRIOC & & 249 & 489 & B \\
\hline VIDRIOE & B & B & B & B \\
\hline VIDRIOS & $\mathrm{P}$ & B & $P$ & $P$ \\
\hline CARBONO HT & B & B & B & B \\
\hline CARBONO HST & $P$ & B & B & B \\
\hline CARBONO HM & $\mathrm{P}$ & B & B & $P$ \\
\hline ARAMIDA & $P$ & B & $P$ & B \\
\hline POLIETILENO & $P$ & B & & $P$ \\
\hline
\end{tabular}


y muy empleada y combinación posible pero poco empleada, quedando las restantes como inadecuadas o no empleadas.

En consecuencia, se puede establecer una relación de buenas parejas de fibras y matrices que es la que se expresa en la Tabla VII.

TABLA VII

Buenas parejas de matrices y fibras para composites

\begin{tabular}{|c|c|}
\hline MATRIZ & FIBRA \\
\hline POLIÉSTER & VIDRIO \\
\hline \multirow{2}{*}{ VINILESTER } & VIDRIO \\
\cline { 2 - 2 } & ARAMIDA \\
\hline \multirow{2}{*}{ EPOXI } & VIDRIO \\
\cline { 2 - 2 } & ARAMIDA \\
\cline { 2 - 2 } & CARBONO \\
\hline FENÓLICA & VIDRIO \\
\hline
\end{tabular}

\section{CARACTERÍSTICAS DE LOS COMPOSITES.}

\subsection{Características generales de los composites}

Las propiedades de estos materiales van en función de la naturaleza de la resina, de la naturaleza del refuerzo elegido y de su presentación, así como de la elección del método de fabricación. Sin embargo, tienen en común ciertas propiedades ligadas a su naturaleza compuesta y a la presencia del refuerzo:

- Anisotropía más o menos marcada según el tipo de refuerzo.

- Baja densidad.

- Características físicas y mecánicas en función de cada uno de los constituyentes y de sus respectivas proporciones.

- Gran resistencia a la corrosión y a la oxidación.

- Propiedades mecánicas elevadas.

- Posibilidad de realizar formas complejas.

- Buenas propiedades cléctricas y dieléctricas (esencialmente los compuestos de fibra de vidrio y resina).

Estos materiales tienen, sin embargo, limitaciones, como, por ejemplo, comportamiento limitado ante la temperatura y el fuego, problemas de envejecimiento (en medios húmedos, bajo la acción de rayos ultravioletas.) y problemas también de fabricación y de unión de piezas.

Las piezas de compuestos no se obtienen generalmente como las piezas de metal o madera. En efecto, los compuestos son heterogéneos y anisótropos. Además, su concepción y puesta en obra requieren una formación previa.

\subsection{Ventajas e inconvenientes de los composites aplica- dos en la construcción}

La elección de materiales puede ser utilizada en la industria de la construcción según numerosos criterios técnicos y económicos. Es por esta razón que los composites más utilizados, en este campo, son a base de resinas (generalmente resinas de poliéster no saturadas) y de fibras de vidrio, porque son los que consiguen una mejor relación calidad/precio. Sin embargo, frente a materiales utilizados tradicionalmente, los compuestos presentan ciertas ventajas (bajo peso, diseños complicados...) pero igualmente ciertos inconvenientes, que, en algunos casos, pueden remediarse, pero que es necesario conocer bien.

A continuación se van a enumerar, de forma esquemática, las ventajas y los inconvenientes o frenos que tienen los composites para que sean aplicados en el campo de la construcción arquitectónica.

\subsubsection{Ventajas}

- Ligereza, ya que sus densidades oscilan entre 0,9 y $2,3 \mathrm{t} / \mathrm{m}^{3}$ (la mayoría de los casos comprendidos entre $1,2 \mathrm{y}$ $1,7 \mathrm{t} / \mathrm{m}^{3}$ ). Ello genera además las ventajas que se derivan del poco peso que tendrían los elementos prefabricados con estos productos: economía y facilidad de transporte, economía y facilidad de manipulación y montaje y, finalmente, reducción de cargas .

- Excelente comportamiento ante la corrosión ambiental, lo que le hace muy apropiado para aplicaciones costeras y marítimas, aplicaciones en ambientes agresivos con mantenimiento prácticamente nulo.

- Una de sus principales ventajas son sus elevadas propiedades mecánicas a tracción, compresión, flexión, cortante e impacto.

- Por otro lado, su moldeabilidad le permite acceder a formas complejas para una fácil reproducción de elementos constructivos (rehabilitación), integración de funciones (estructural, cierre, aislante, acabado...) con la utilización de numerosas técnicas de fabricación.

- Posibilidad de moldeo en grandes piezas con pocas limitaciones y con aplicaciones de difícil ejecución con materiales tradicionales.

- Numerosos acabados: mates, rugosos, satinados, color en masa, grados de transparencia, translucidez, opacidad...

- Son materiales autolimpiables por la lluvia, por lo que resulta muy interesante para elementos arquitectónicos exteriores como fachadas, elementos decorativos, cubiertas... - No presentan interferencia a las ondas electromagnéticas, por lo que son unos materiales idóneos para edificios de comunicaciones y transmisiones.

- Resistentes al fuego y de baja inflamabilidad, mediante una selección adecuada de resinas y aditivos.

- Baja conductividad térmica, que los hace ideales para resolver problemas de aislamiento térmico.

- Coloración en masa. Pueden pigmentarse en el proceso de fabricación, por lo que no necesitan pintarse. 
- Inertes al agua y a los agentes químicos, que hace que se usen masivamente en las instalaciones de almacenaje, distribución y transporte de productos químicos y de mercancías peligrosas

- Pueden ser buenos aislantes acústicos, utilizando aditivos específicos y dándoles una conformación y diseño adecuados para que sean utilizados con tal fin en la construcción.

-Excelentes aislantes eléctricos, que los hacen recomendables para instalaciones de almacenaje, distribución y transporte en la industria eléctrica, consiguiendo la eliminación de aisladores.

- No son nocivos, como puede ser el amianto, sustituyendo a éste en las placas onduladas.

- Son materiales seguros y estables. Ante un incendio o cargas extremas no se produce la rotura total del material, conservándose unido.

\subsubsection{Desventajas}

- Coste elevado, aunque con un diseño adecuado que aproveche su ligereza, economía de transporte, manipulación y montaje, reducción de cargas, mantenimiento casi nulo, eliminación del pintado e integración de funciones, puede ser un elemento constructivo rentable en comparación con otros elementos convencionales.

- Desconocimiento de los materiales composites, tanto en lo que se refiere a la falta de formación de los futuros técnicos y aplicadores como falta de información en general sobre sus características y posibilidades de aplicación.

- Falta de reglamentación de uso o normativa técnica, lo que da inseguridad para su diseño y cálculo.

- Falta de información sobre su durabilidad, ya que se trata de materiales muy jóvenes, poco usados hasta ahora, por lo que el arquitecto, agobiado por su responsabilidad decenal, prefiere no arriesgar.

- Baja resistencia al calor. No obstante puede minimizarse utilizando los componentes apropiados y añadiéndole los aditivos precisos.
- Mal comportamiento ante los rayos UV, aunque puede ser contrarrestado este efecto utilizando los aditivos adecuados.

- Falta de clasificación al fuego. Aunque su comportamiento ante el fuego no es malo, la falta de clasificación reprime su uso.

- Son materiales de difícil reciclaje, no obstante, las más recientes investigaciones están consiguiendo avances muy importantes, por ejemplo: se someten a tratamientos mecánicos y posterior trituración para usarse como carga en otros composites o materiales de construcción.

- Falta de mentalización entre usuarios y técnicos.

- Conservadurismo tradicional en el sector de la construcción, que hace muy difícil la introducción de nuevos materiales o nuevas tecnologías, si no llevan aparejado un beneficio económico para el constructor.

\section{APLICACIONES DE LOS COMPOSITES EN LA EDIFICACIÓN}

En los años 40 comienzan a utilizarse los composites en diversas industrias, teniendo un amplio desarrollo en el campo de la aeronática y en diversas aplicaciones bélicas, de tal forma que ya en los años 60 todos los aviones incorporan algún material composite.

De las aplicaciones bélicas primero y aeroespaciales después se pasa, con la industrialización y abaratamiento, a la utilización en otros campos de la industria, y así en los años 80 se utilizan ya cientos de toneladas en transporte, electricidad, deporte, etc. No obstante las aplicaciones de los composites en el campo de la edificación, aunque ha habido alguna aplicación puntual con anterioridad, no empieza a interesar hasta hace unos pocos años.

Los materiales compuestos se aplican actualmente en todos sectores de la industria, el deporte, la construcción, etc. en las proporciones y con las características que se indican a continuación (Figura 8).
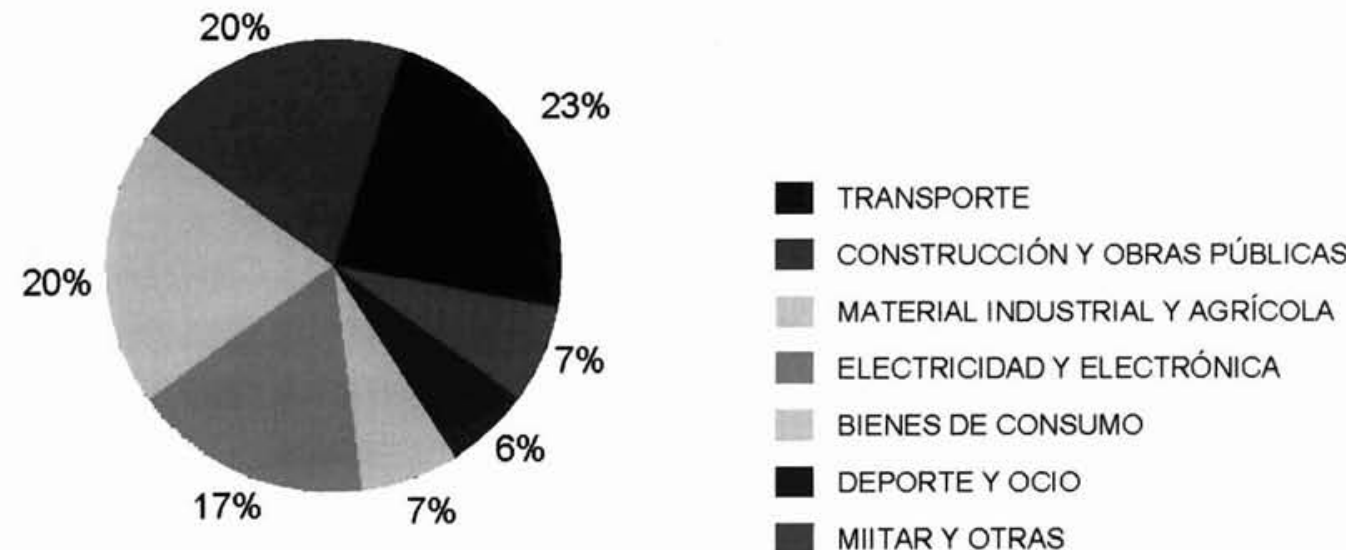

Figura 8. - Aplicación de los composites en diferentes sectores. 
La introducción de los composites en una industria tan conservadora como la construcción no es nada fácil. Esto explica que dichos materiales se hayan aplicado tan poco en este sector. Sin embargo, desde su aparición, los compuestos fibra de vidrio-resina, conocidos bajo el nombre de plásticos reforzados o $P R V$, han revelado tal flexibilidad de uso que se han intentado numerosas experiencias en la construcción. No obstante, a pesar de los numerosos aspectos positivos presentados por estos materiales, no ha habido una generalización de estas realizaciones. Al entusiasmo del descubrimiento de unos nuevos materiales de unas características muy singulares se oponía el problema de durabilidad de los mismos y de su resistencia al fuego. Estos problemas están casi resueltos actualmente y asistimos a un nuevo desarrollo de los composites en la industria de la construcción.

Los sistemas y elementos constructivos en los que se están usando los materiales compuestos en la actualidad se pueden clasificar en:

\subsection{Cubiertas y tejados}

$\mathrm{Al}$ contrario de lo que ocurre con los materiales utilizados habitualmente en las coberturas, las piezas de composite pueden tener cualquier forma o dimensión y pueden ser translúcidas. Además, si se tiene en cuenta que poseen una buena resistencia mecánica y una baja densidad se constituyen en unos materiales de unas muy buenas características para ser utilizados en la realización de grandes tejados (Figuras 9, 10 y 11).

Las resinas de poliéster son translúcidas cuando son utilizadas sin pigmento y sin carga y la incorporación controlada de la fibra de vidrio no altera la transmisión de la luz. Por esta razón los composites aparecieron en la construcción a partir de 1956 en la realización de placas translúcidas para iluminación industrial. Luego, las aplicaciones no han parado de crecer y continúan todavia desarrollándose para la iluminación cenital y la cobertura de grandes espacios con cúpulas "acristaladas" (Figuras 12, 13, 14 y 15). También, las cubiertas textiles utilizan hoy dia telas de composite casi exclusivamente.

\subsection{Estructuras}

No han sido muchas las aplicaciones de los materiales compuestos en elementos estructurales de edificios, aunque su uso en la ingeniería civil, sobre todo en puentes y pasarelas es actualmente muy frecuente. Sin embargo, una de las primeras aplicaciones de los composites fue la construcción en el año 1940, en Inglaterra, de unas casetas de poliéster reforzado con fibra de vidrio para alojamiento de radares. La decisión de utilizar estos materiales en estructuras edificatorias es fundamentalmente por su propiedad de ser transparentes a las ondas electromagnéticas, al contrario de lo que ocurre con las estructuras metálicas y los tornillos que las unen. En este tipo de estructuras, tanto los pilares como las vigas y los tornillos de unión, han sido realizados en composite por pultrusión, técnica que permite unos elementos de forma y sección constante.

Actualmente, las resinas epoxi reforzadas con fibra de carbono constituyen un método muy usado en la reparación de estructuras de hormigón (Figuras 16,17 y 18).

\subsection{Paneles de fachada}

Los paneles de fachada, son ampliamente utilizados en la construcción, tanto en edificios nuevos como en rehabilitación. Representan la mayoría de la utilización de los composites de resina-fibra de vidrio en este sector $(40 \%$ en USA y el $50 \%$ en Europa). Su utilización está fomentada por las grandes ventajas que tienen estos materiales para estas aplicaciones: buena resistencia mecánica, buena estabilidad química y térmica, bajo peso, aligeramiento de

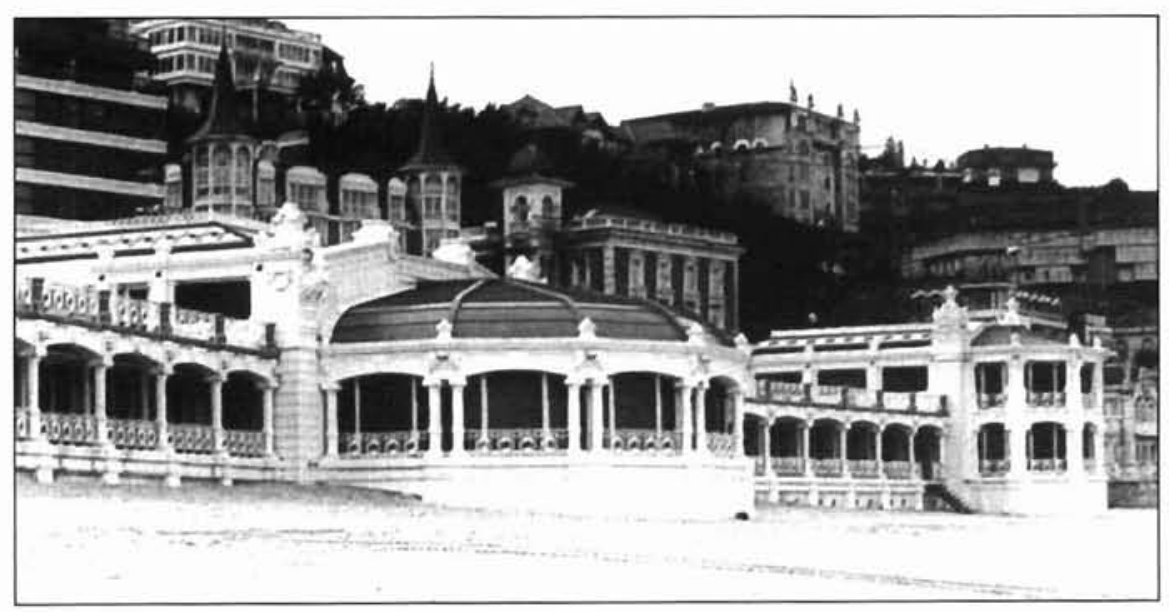

Figura 9.- Aplicación de los composites en tejados y cubiertas ${ }^{\circ}$. 

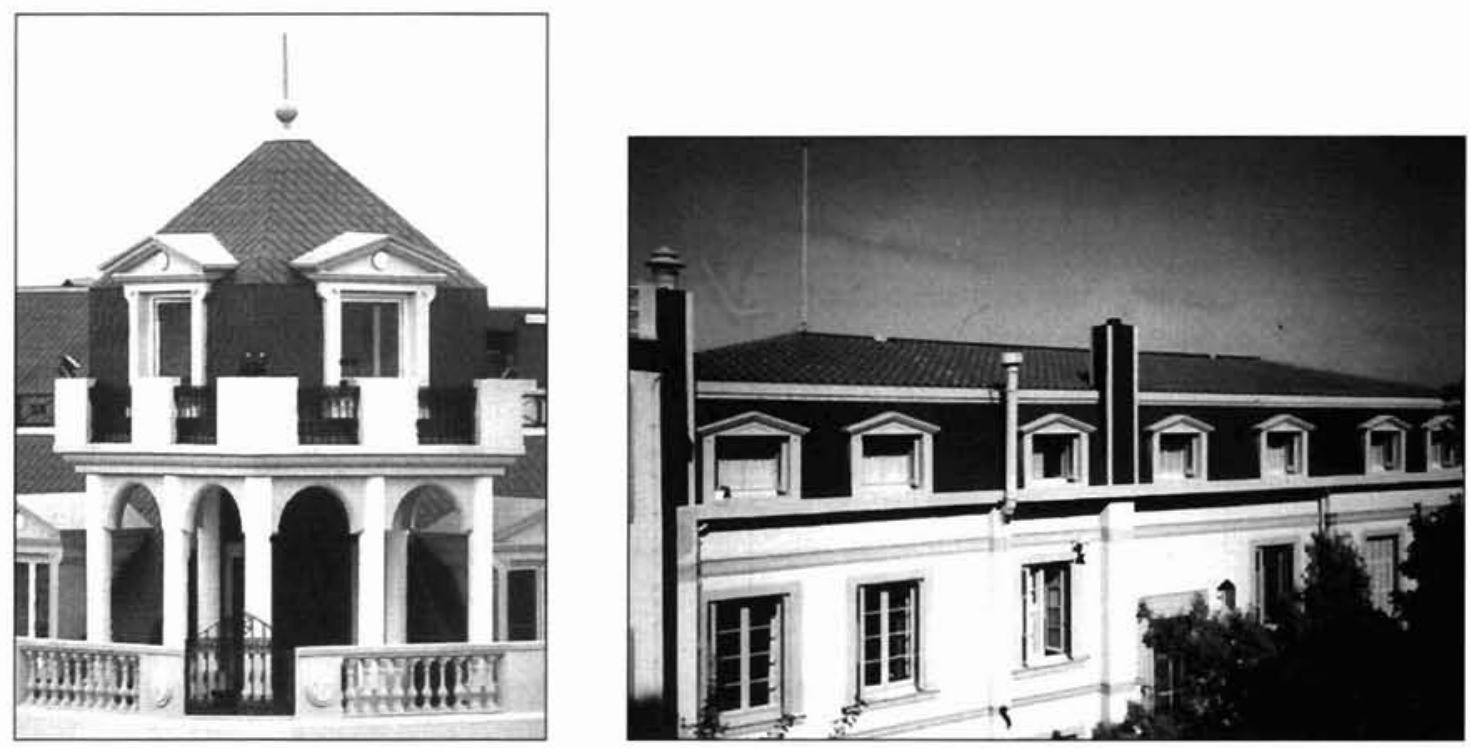

Figuras 10 y 11.-Aplicación de los composites en tejados y cubiertas $\%$.
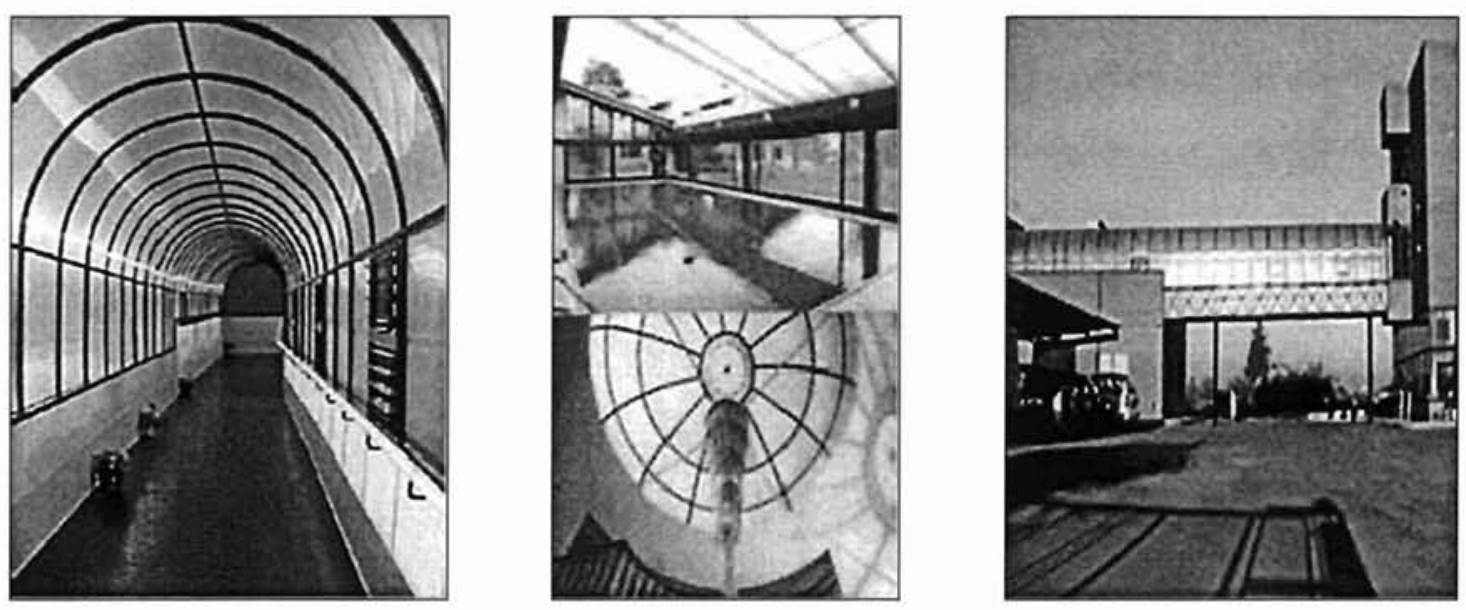

Figuras 12, 13 y 14.- Aplicación de los composites en cubiertas translúcidas.
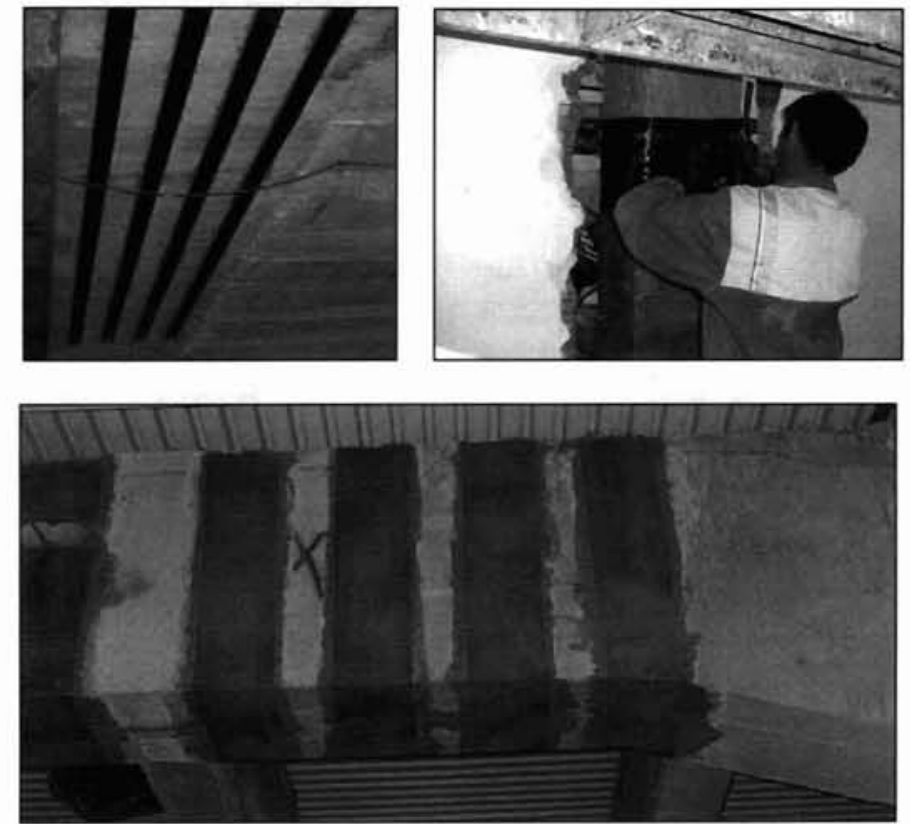

Figuras 16, 17 y 18.- Aplicación de los composites en reparación de estructuras. 
las estructuras, manipulación sencilla y mantenimiento casi nulo. (Figuras 19, 20, 21, 22 y 23)

\section{4. Rehabilitación de fachadas}

Las posibilidades de moldeo, y la capacidad de coloración y texturizado, permiten reproducir muy fácilmente la conformación arquitectónica del edificio que hay que rehabilitar (Figuras 24 y 25).

\section{5. Recercados de ventanas y protección solar}

La utilización de los materiales composites en la fabricación de bastidores y marcos de puertas y ventanas está ac- tualmente en sus inicios. Los perfiles pultrusionados de compuestos de resina-fibra de vidrio, tienen unas caracteristicas muy adecuadas para este tipo de aplicación: facilidad de instalación, poco sensibles a las variaciones térmicas, coeficiente de dilatación prácticamente idéntico al de los cristales, larga vida, nulo mantenimiento y buen aislante térmico (Figura 26).

\section{6. Sanitarios y mobiliario interior}

Incluimos en este apartado desde las piscinas prefabricadas hasta los fregaderos, pasando por las bañeras, duchas y baños integrados. Las ventajas que ofrecen los composites en la fabricación de estos elementos, en relación con los

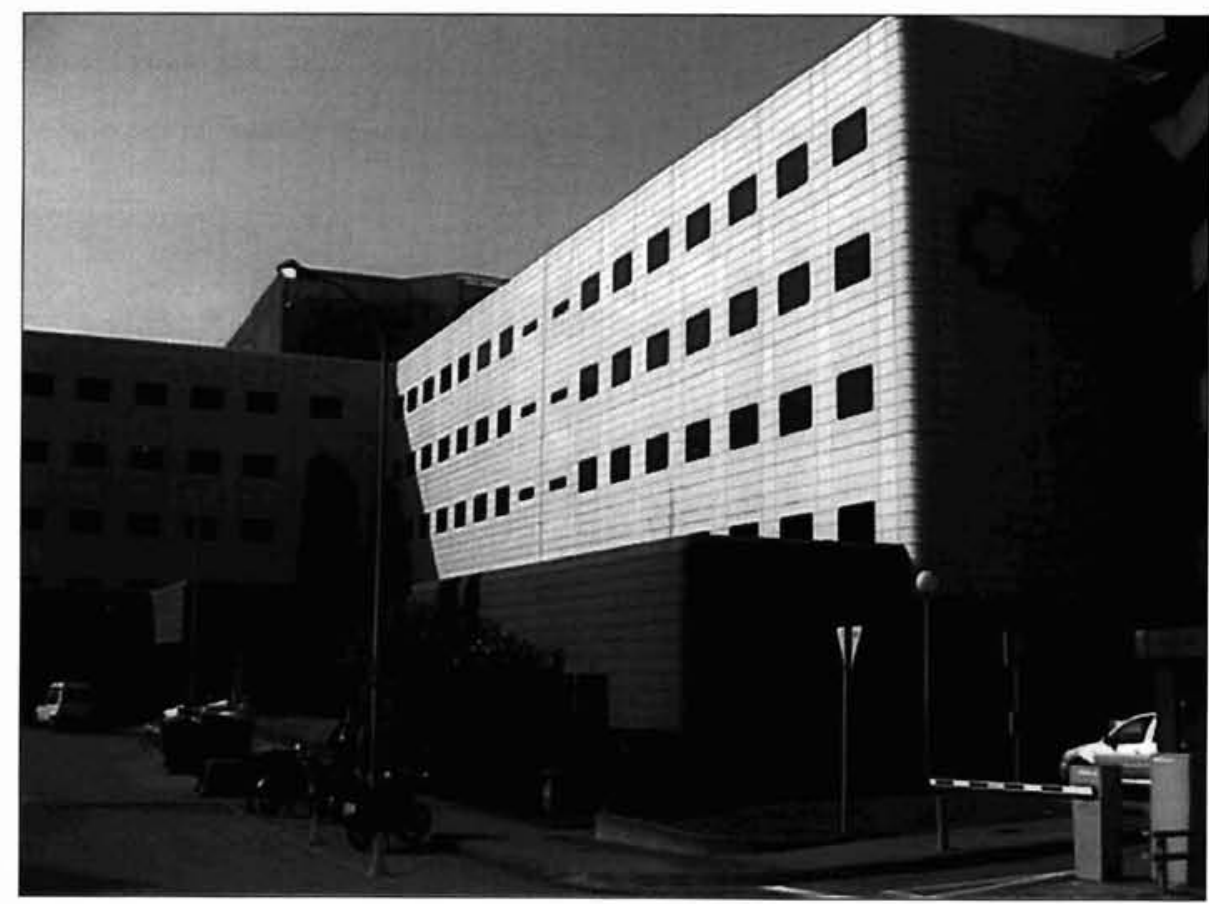

Figura 19.- Hospital General de Cataluña en Barcelona.
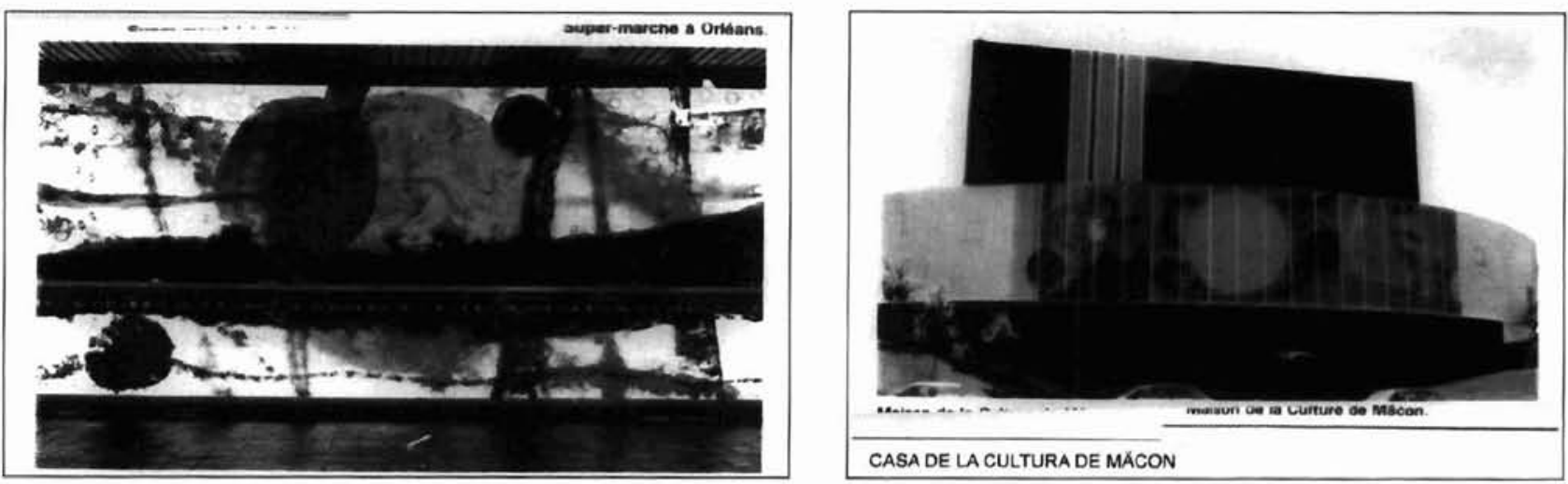

Figuras 20 y 21. Ejemplos de paneles translúcidos de composite (supermercado en Orléans y casa de la cultura en Mäcon). 

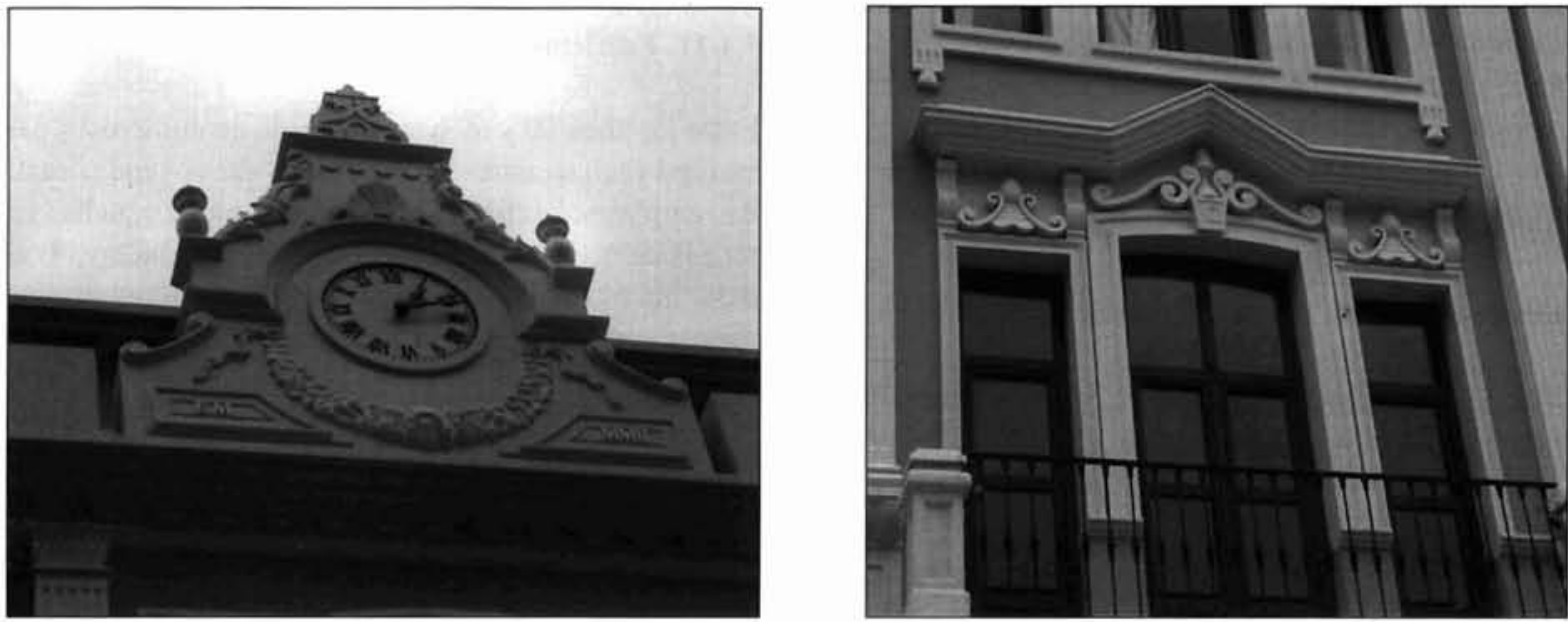

Figuras 22 y 23.- Aplicación de los composites en paneles de fachadas. Hotel en Portugalete ${ }^{(\%)}$

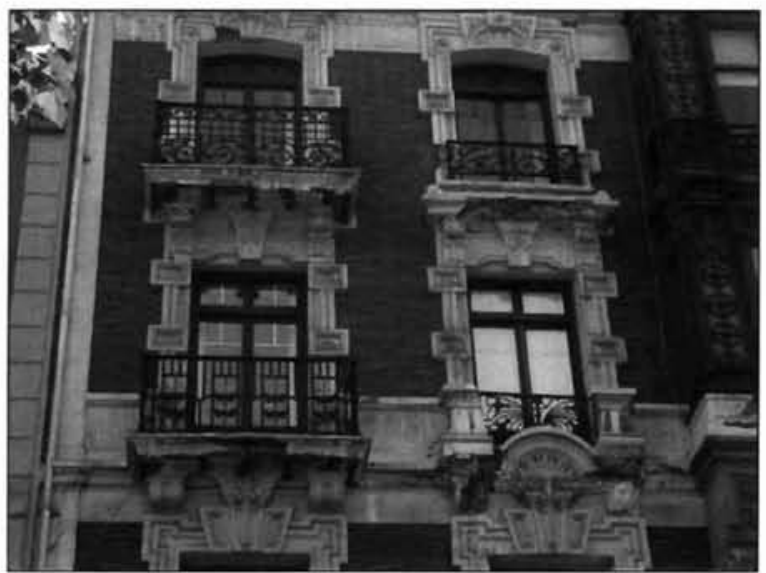

Figura 24.- Fachada antes de ser rehabilitada $(\%)$

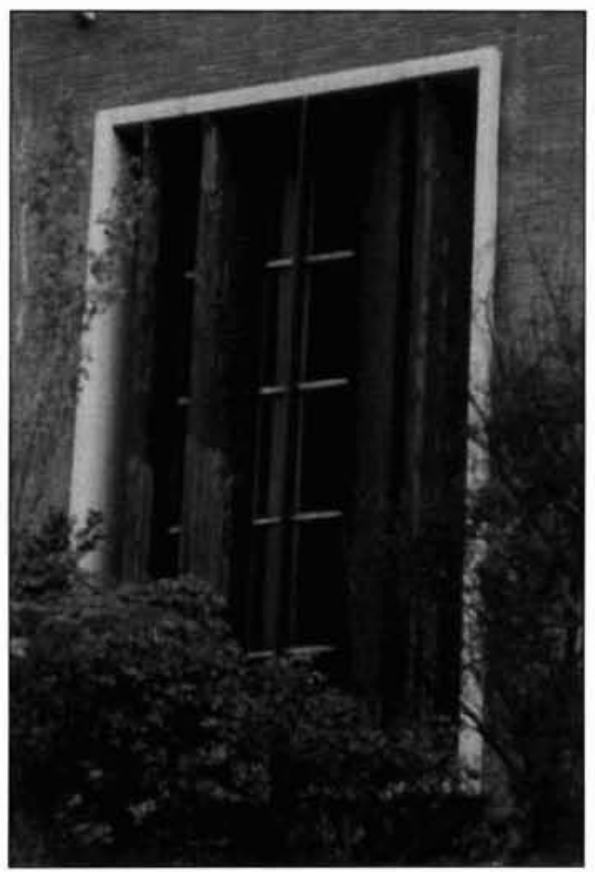

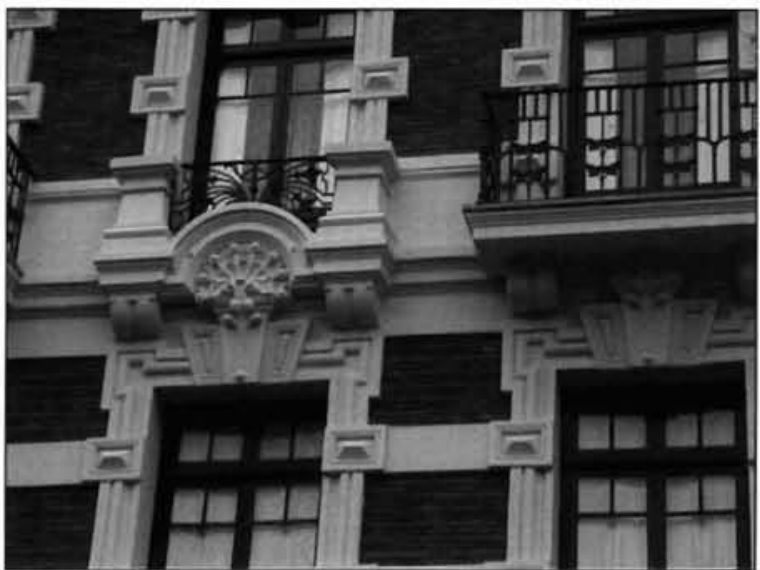

Figura 25.- Fachada después de ser rehabilitada con materiales composites $"$ ").

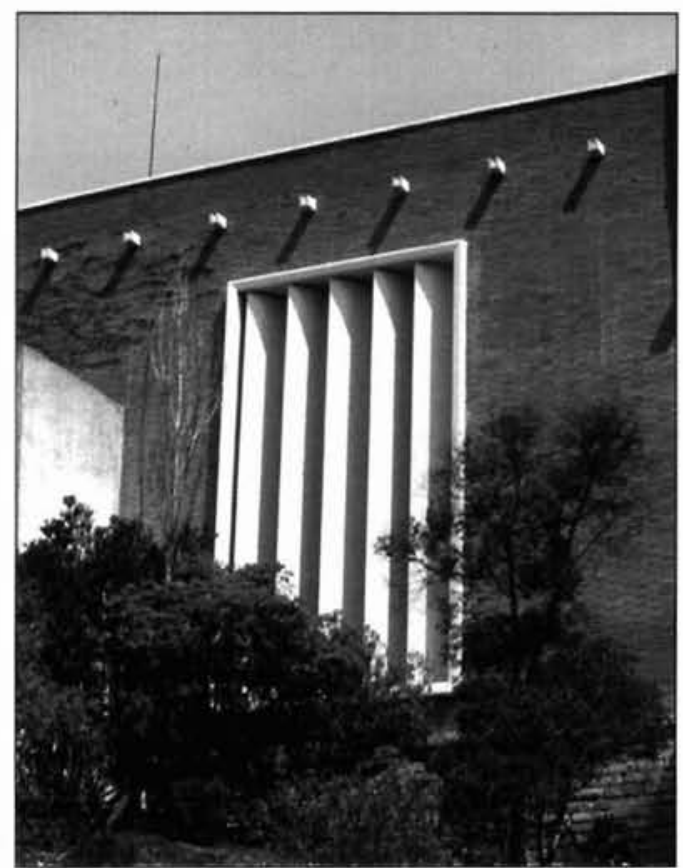

Figura 26. - Aplicación de los composites en ventanas y lamas. Sustitución de elementos deteriorados a la intemperie por elementos de composite (Instituto Eduardo Torroja) ${ }^{(\%)}$. 
materiales convencionales son: bajo peso, resistencia a la corrosión, resistencia a los golpes, fácil instalación, precio competitivo, estética (al poder conseguirse cualquier tipo de formas y colores), baja conductividad térmica y gran confort acústico (Figura 27).

\section{7. Impermeabilización de cubiertas}

Los composites con matriz polimérica, generalmente PVC o similares, son muy utilizados en impermeabilizaciones de cubiertas, gracias a sus propiedades frente al agua a su elasticidad y su técnica de colocación (Figuras 28, 29 y $30)$.

\section{8. Electricidad}

Los composites con matriz polimérica, generalmente resina de poliéster o epoxi reforzadas con fibra de vidrio, son muy utilizados en las aplicaciones eléctricas por sus características dieléctricas y su ligereza, fundamentalmente.

\section{9. Encofrados}

Los encofrados o moldes para hormigón en compuestos son utilizados para el moldeado de piezas prefabricadas o realizadas en obra. Son ligeros, fáciles de manipular, de larga duración.

\section{10. Elementos de seguridad en obra}

Se realizan con los composites escaleras, barandillas y otros elementos de seguridad en obra ya que son de fácil instalación, poco peso, resistentes a todos los ambientes y no necesitan mantenimiento

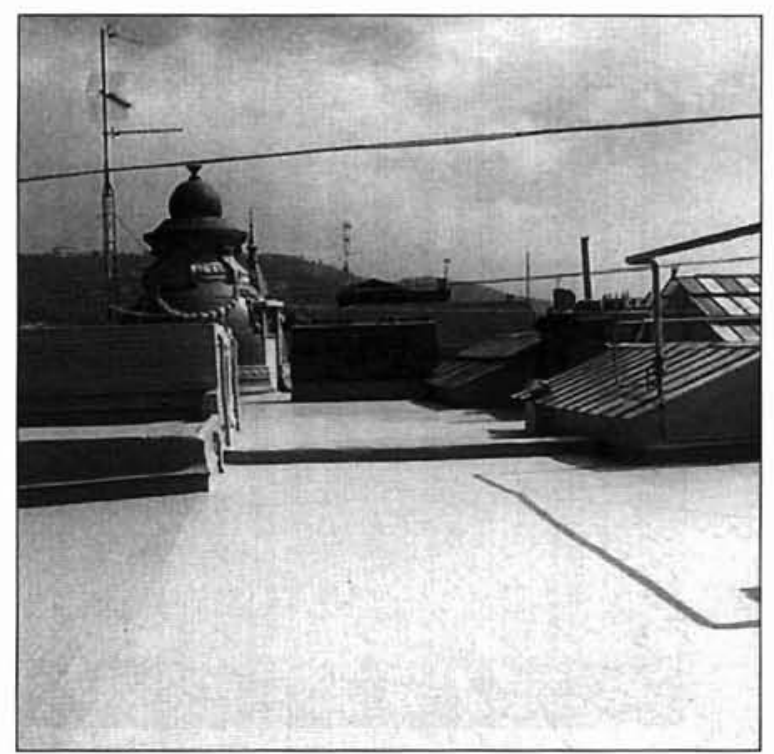

\subsection{Edificios en composites}

Entre los años 50 y 60 han aparecido en numerosos paises muchas realizaciones de prototipos de viviendas realizadas en plástico reforzado. Se tenian puesta muchas esperanzas en estos materiales ya que los diseñadores podian dejar libre la imaginación para conseguir cualquier tipo de formas, debido a la gran flexibilidad de los mismos. Sin embargo, era el comienzo de los composites y las características de estos materiales estaban muy lejos de cubrir todas las exigencias y garantías exigidas para una vivienda.

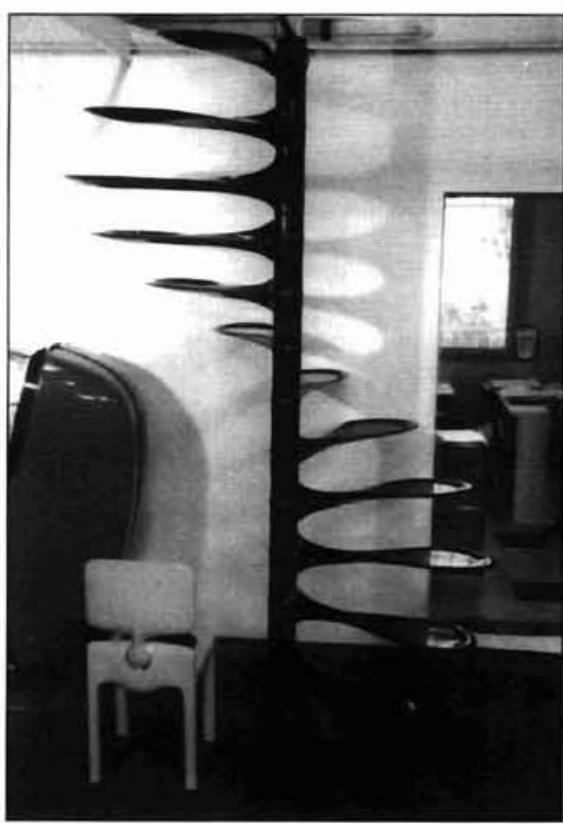

Figura 27.- Aplicación de los composites en mobiliario interior (silla y escalera de caracol).

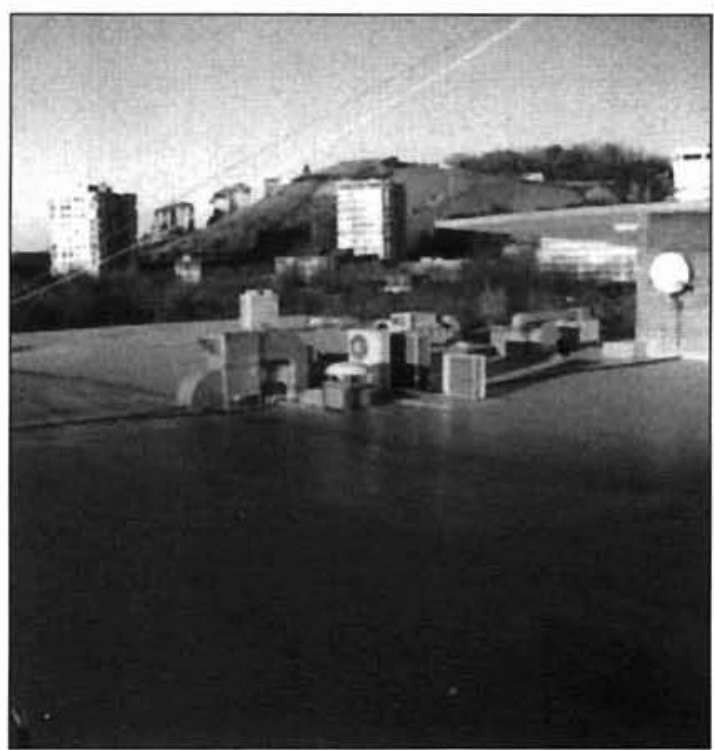




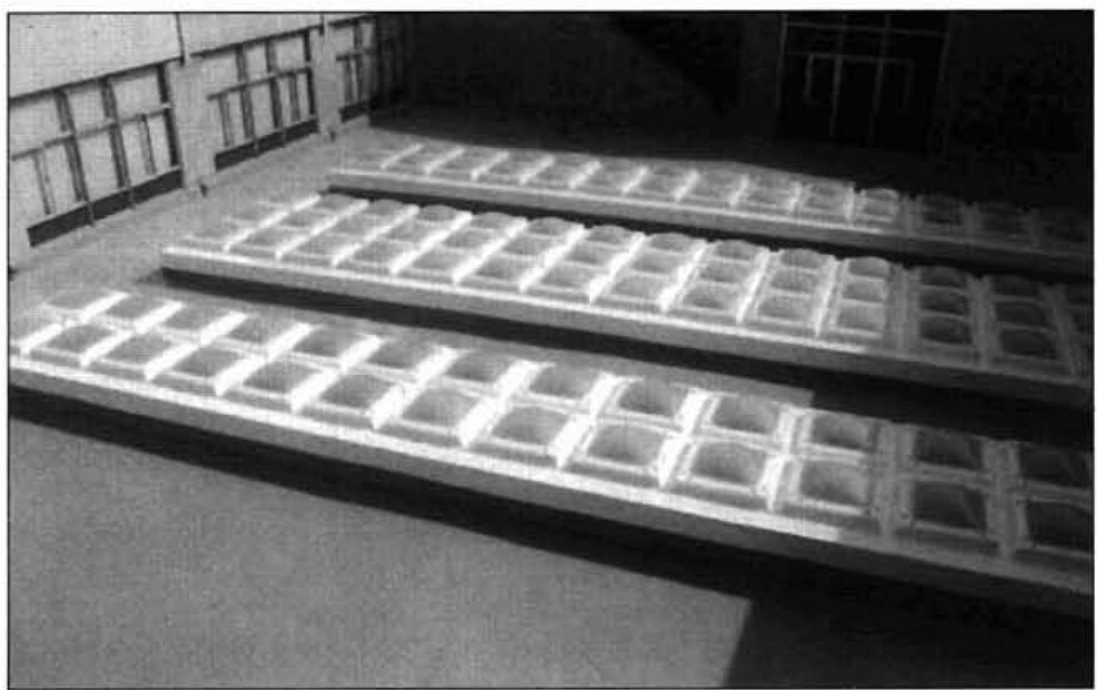

Figura 30.- Aplicación de los composites en impermeabilización de cubiertas (").

Hoy día la mayoría de los problemas presentados han sido ya resueltos y nos encontramos ante un campo importante de aplicación de los composites, que permite la construc- ción de edificios ligeros, reproducibles, modulables, fácilmente transportable y que no necesitan en muchos casos cimentación. (Figuras 31, 32 y 33 )

(") Fotografias cedidas por Composites Jareño S. L.

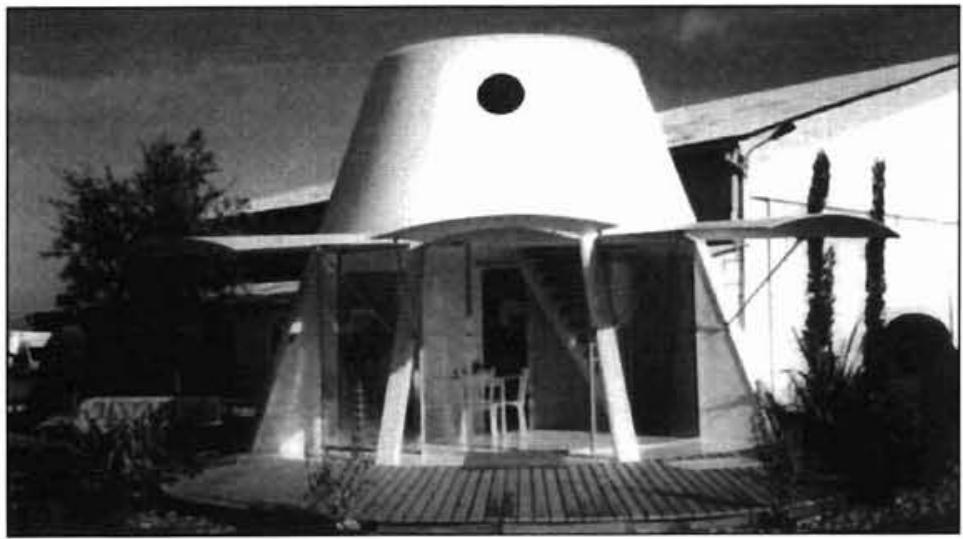

Figura 31.- Aplicación de los composites en edificios completos (vivienda en Burdeos diseñada por el arquitecto Jean de Giacinto).

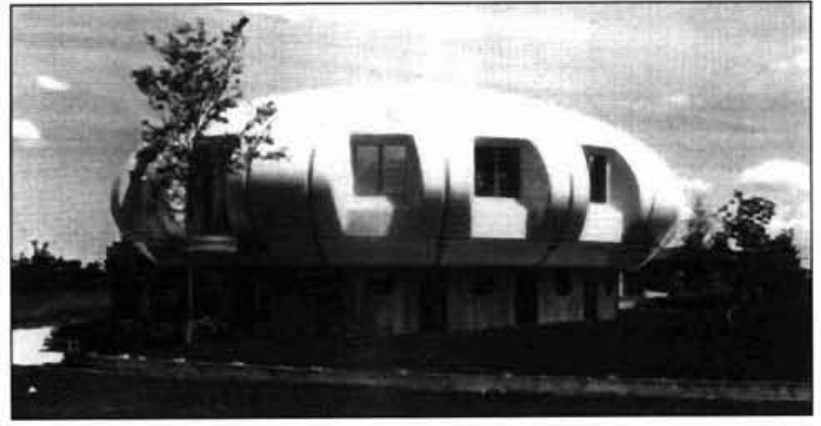

Figura 32.- Aplicación de los composites en edificios completos (vivienda al norte de Venecia).

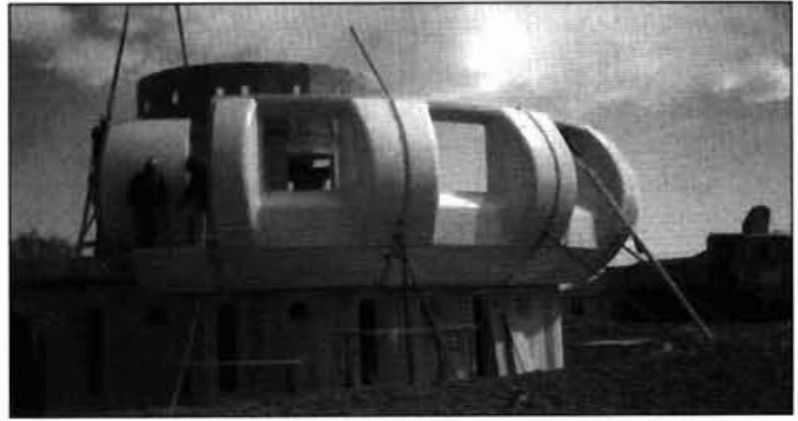

Figura 33.- Proceso de montaje. 
Informes de la Construcción, Vol. 54, $\mathrm{n}^{\circ} 484$, marzo-abril 2003

\section{BIBLIOGRAFÍA}

AEMAC. Actas del I Congreso Nacional de materiales compuestos. (1995). Sevilla.

ANTEQUERA, JIMÉNEZ, MIRAVETE (1991). “Los materiales compuestos de fibra de vidrio”. Univ. de Zaragoza.

ARQUIMACOM'96 (octubre 1996) Libro de Actas de la 1" Conferencia Internacional de los materiales compuestos aplicados en Arquitectura y Construcción. Sevilla.

BAKIS, C. E., BANK, L.C., BROWN, V. L., COSENZA, E., DAVALOS, J. F., LESKO, J. J., MACHIDA, A., RIZKALLA, S. H. AND TRIANTAFILLOU, T. C. (2002) Fiber-Reinforced Polymer Composites for Construction-State-of-the-Art Review. Journal of Composites for Construction. May 2002. Volume 6, Issue 2, pp. 73-87.

BANK, L.C., GENTRY, T.R., THOMPSON, B.P. AND RUSSELL, J. S. (2002), “A Model Specification for Composites for Civil Engineering Structures," Transportation Research Record No.1814, Journal of the Transportation Research Board, pp. 227-236.

INASMET. "Materiales compuestos. Tecnologias de producción". Centro Tecnológico de materiales Compuestos.

GAGNE, S. I. (2000) "Fiber Reinforced Plastic Joists for the Construction Industry-A Feasibility Study," MS,

LAFFARGA, J., OLIVARES, M. (1995). "Materiales de construcción”. Editan. Sevilla.

MARTINEAU, PH. (1987). "Materiaux composites et industrie. Les materiaux composites dans le batiment ). "Institut des materiaux composites. Burdeos.

MIRAVETE, A. (1994). “Los nuevos materiales en la construcción.” Univ. Zaragoza.

MIRAVETE, A., LARRODÉ, E., CASTEJÓN, L., CUARTERO, J. (2000). "Materiales compuestos". Ed. A. Miravete, Zaragoza.

OLIVARES SANTIAGO, M. (1997). "Composites: los nuevos materiales de la construcción. Composición y características técnicas". In: Façanes lleugeres, els nous plafons. Col. Legi d'aparelladors i arquitectes tècnis de Barcelona. Barcelona. 